(C) 2022, The Authors. Published by Elsevier Inc. and Fass Inc. on behalf of the American Dairy Science Association ${ }^{\circledR}$. This is an open access article under the CC BY license (http://creativecommons.org/licenses/by/4.0/).

\title{
Cytological endometritis diagnosis in primiparous versus multiparous dairy cows
}

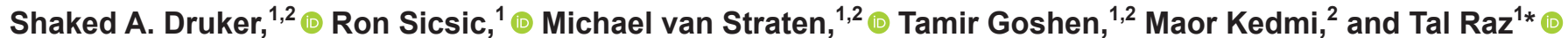 \\ ${ }^{1}$ Koret School of Veterinary Medicine, Robert H. Smith Faculty of Agriculture, Food and Environment, The Hebrew University of Jerusalem, \\ Rehovot 76100 , Israel \\ ${ }^{2}$ Hachaklait, Mutual Society for Veterinary Services, Caesarea Industrial Park 3079548, Israel
}

\begin{abstract}
Endometritis is a uterine disease of dairy cows causing substantial negative effects on reproductive performance and inflicting considerable economic losses. It is typically diagnosed by endometrial cytology evaluation and commonly named cytological endometritis (CEM). In most previous studies, cows were defined as CEM positive if the proportion of polymorphonuclear cells $(\% \mathrm{PMN})$ in their endometrial cytology was above a pre-set threshold. Thresholds were established based on CEM diagnosis in association with reproductive performance, typically analyzed by a single reproductive parameter and calculated for all cows together. Our objective was to examine whether primiparous and multiparous cows should optimally be diagnosed for CEM by different \%PMN thresholds and sampling timings, using a combination of several reproductive performance parameters. Two endometrial cytobrush cytology samples were collected from Holstein-Friesian dairy cows ( $\mathrm{n}=415 ; 269$ multiparous; 146 primiparous), at $30-40 \mathrm{~d}$ in milk (DIM) and 60-70 DIM, and \%PMN were evaluated microscopically (blindly; Diff-Quick stain, Medi-Market). The \%PMN thresholds were set at $\geq 1 \%$ to $\geq 10 \%, \geq 15 \%$, and $\geq 20 \%$, and accordingly, for each of the thresholds, several reproductive performance parameters were compared between CEMpositive versus CEM-negative cows. Upon application of several analytic approaches, our results indicated that optimal CEM diagnosis should be performed by different criteria in primiparous and multiparous cows: in primiparous cows at 30-40 DIM, using a threshold of $\geq 7 \% \mathrm{PMN}$, and in multiparous cows at 60-70 DIM, using a threshold of $\geq 4 \% \mathrm{PMN}$. Such a diagnostic approach provides a comprehensive view of the repro-
\end{abstract}

Received December 21, 2020.

Accepted September 15, 2021.

*Corresponding author: tal.raz@mail.huji.ac.il ductive prognosis of CEM-positive primiparous and multiparous cows, which is pertinent information for researchers, veterinarians, and farmers.

Key words: dairy cows, endometritis, endometrium, polymorphonuclear cells, parity

\section{INTRODUCTION}

Postpartum uterine diseases in dairy cows, particularly metritis and endometritis, have a pronounced influence on dairy farm economics, primarily through decreased reproductive performance parameters (LeBlanc et al., 2002; LeBlanc, 2008). Whereas metritis is typically diagnosed within the first 2 or 3 wk postpartum by the presence of fetid purulent or mucopurulent vaginal discharges and enlarged uterus, endometritis is diagnosed later in lactation (Sheldon et al., 2006). Clinical endometritis can be diagnosed by the presence of purulent vaginal discharge and other parameters, as previously described (Williams et al., 2005; Wagener et al., 2017). Another technique for diagnosing endometritis is microscopic evaluation of endometrial cytology smears, sampled by an endometrial cytobrush (Kasimanickam et al., 2004; Barlund et al., 2008; Pothmann et al., 2019), low-volume uterine lavage (Gilbert et al., 2005; Cheong et al., 2011; Van Schyndel et al., 2018), or Cytotape (Pascottini et al., 2015). When endometritis is diagnosed using cytological techniques, the term "subclinical endometritis" is commonly used if there are no signs of clinical endometritis in vaginal examination (i.e., purulent vaginal discharge). However, because of the poor correlation between vaginal discharge and cytological findings, the term "cytological endometritis" (CEM) was suggested (Dubuc et al., 2010a; McDougall et al., 2011). Diagnosis of CEM is based on the presence and proportions of polymorphonuclear cells (\% PMN) among the nucleated cells in endometrial cytology smear. This method also aims to detect subclinical cases, which are common among dairy cows (Plöntzke et al., 2010; Barański et al., 2012; Deguillaume et al., 2012). 
The use of endometrial cytobrush for endometrial cytology smear was first described by Kasimanickam et al. (2004), who defined cows as positive for subclinical endometritis if they had $\geq 18 \%$ or $\geq 10 \%$ PMN in their cytology smears, at 20-33 DIM or 34-37 DIM, respectively. A year later, the same group compared between the endometrial cytobrush technique to the low-volume uterine lavage technique for collecting samples for endometrial cytology and concluded that the cytobrush technique was more reliable (Kasimanickam et al., 2005). Later, Barlund et al. (2008) compared 5 methods for assessing subclinical endometritis, 2 of which were based on endometrial cytology collecting procedures: low-volume uterine lavage and endometrial cytobrush. They also reported endometrial cytobrush to be more reliable than low-volume lavage, with higher intraobserver repeatability. Accordingly, endometrial cytobrush has been commonly used in cytological endometritis studies since (Kaufmann et al., 2010; Barański et al., 2012; Deguillaume et al., 2012).

Interestingly, an inspection of recent studies revealed that the prevalence of CEM vastly varies among different studies, ranging from $6 \%$ to $45 \%$ (Plöntzke et al., 2010; Barański et al., 2012; Deguillaume et al., 2012). This range can be related to the diversity among cow herds. However, it may also be related to the criteria used for diagnoses, including the \% PMN threshold used to define endometritis (ranging from 1\% to 18\%), the time of sampling in lactation (in relation to calving), and the cow parity (de Boer et al., 2014). In most previous studies, the \%PMN threshold has been established based on retrospective analyses of the CEM diagnosis association with reproductive performance, typically by using a single outcome measure. In those studies, open days (i.e., number of days from calving to conception) was the most commonly used reproductive performance reference, whereas other parameters were overlooked in the analysis that established the \%PMN threshold. The ideal reproductive performance parameter should reflect the physiological ability to become pregnant at an optimal time from calving (LeBlanc, 2010). However, any sole reproductive performance parameter may be confounded by farm management, estrus detection methods, insemination techniques, time of pregnancy examination, and other factors; and possibly in different magnitude and direction from one to another. Multivariable survival analysis is considered the fittest method for analyzing pregnancy data (Weigel, 2004). Analysis of calving to pregnancy interval combines the calving to first insemination interval and the first insemination to pregnancy interval, each of which can be affected by different nonphysiological parameters. Analyses of proportions diagnosed pregnant by different postpartum times (e.g., pregnancy risk at 180 DIM), or following insemination (e.g., first AI pregnancy risk), add additional value; however, these parameters can also be affected by different nonphysiological parameters. Therefore, analyses of several reproductive performance parameters (i.e., survival analysis of those intervals as well as pregnancy risk analyses) are expected to provide a comprehensive view of an individual cow's reproductive status. Furthermore, CEM diagnosis can potentially be associated with differences in several reproductive performance parameters when comparing cows defined as having CEM (CEM-positive cows) to cows considered healthy (CEM-negative cows).

Dubuc et al. (2010a) found that the optimal threshold for defining CEM at $32-38$ DIM was $\geq 6 \%$ PMN, whereas at 53-59 DIM, they found that a threshold of $\geq 4 \%$ PMN was the most suitable, confirming that the \% PMN threshold decreases as the interval from calving increases, in agreement with other reports (Kasimanickam et al., 2004; Madoz et al., 2013). Cow parity is another factor that may potentially affect the defined PMN percent threshold. Primiparous and multiparous cows differ in many aspects, such as postpartum uterine involution (Bastidas et al., 1984; Melendez et al., 2004; Zhang et al., 2010), metabolism and energy balance (Morales Piñeyrúa et al., 2018; Gärtner et al., 2019; Yehia et al., 2020), milk production (Morales Piñeyrúa et al., 2018; Ben Meir et al., 2019; O'Sullivan et al., 2019), ovarian function (Tanaka et al., 2008; López-Helguera et al., 2016; Morales Piñeyrúa et al., 2018), reproductive performance (Fodor et al., 2019; Rojas Canadas et al., 2020), and management (McDougall et al., 2014). Therefore, several of the studies cited above accounted for the cows' parity in their statistical models (whether it was primiparous or multiparous) while establishing a \% PMN threshold for the diagnosis of CEM in all cows together (Kasimanickam et al., 2004; Barlund et al., 2008; Madoz et al., 2013). However, to the best of our knowledge, none of the previous studies profoundly explored the possibility of establishing different diagnostic criteria for primiparous versus multiparous cows by using several selected reproductive performance parameters (instead of using a single parameter).

Therefore, our study objective was to examine whether primiparous and multiparous cows should optimally be diagnosed for CEM by different \% PMN thresholds and at different sampling times in lactation. We hypothesized that for optimal CEM diagnosis, the \%PMN threshold and sampling timing differ between primiparous and multiparous cows. We argue that refining the parameters that will suit primiparous and multiparous will provide a more accurate diagnosis with valuable information for further CEM research, 
treatment's decision-making process, and breeding program management, for researchers, veterinarians, and farmers.

\section{MATERIALS AND METHODS}

\section{Animals and General Management}

The study was conducted according to the ethical approval of the Hebrew University's Institutional Animal Care and Use Committee (MD-13-13807-2). Licensed veterinarians performed all animal procedures with the consent of the animal owner given before enrollment. The number of cows in the study was calculated by parity group using an online Sample Size Estimation calculator available from Johns Hopkins University (School of Medicine, Baltimore, MD), with a 2-tailed hypothesis, a significance level of $P=0.05$, and a power of $80 \%$. For multiparous cows, it was calculated to detect a difference of approximately $25 \%$ in the proportion diagnosed pregnant up to 180 DIM between CEM-negative to CEM-positive cows (65\% vs. $40 \%$, respectively; based on preliminary results) as the main outcome. For primiparous cows, it was calculated to detect a difference of approximately $30 \%$ in the proportion diagnosed pregnant up to 180 DIM between CEM-negative to CEM-positive cows (65\% vs. $35 \%$, respectively; based on preliminary results) as the main outcome. Accordingly, a total of 415 postpartum Israeli Holstein-Friesian cows (269 multiparous; 146 primiparous) from 5 commercial farms in central and southern Israel (Nahshonim, $32^{\circ} 06^{\prime} \mathrm{N} 34^{\circ} 95^{\prime} \mathrm{E}$; Be'erot Yitshak, $32^{\circ} 02^{\prime} \mathrm{N} 34^{\circ} 54^{\prime} \mathrm{E}$;

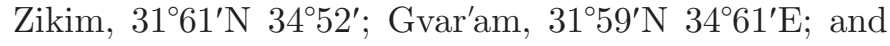
Dorot, $31^{\circ} 50^{\prime} \mathrm{N} 34^{\circ} 65^{\prime} \mathrm{E}$; Supplemental Table S1, https:/ /doi.org/10.5281/zenodo.5507320, Druker et al., 2021) partook in this prospective longitudinal study from May 2014 to October 2019. Cows were housed in a loose-housing barn (bedded area $\sim 20 \mathrm{~m}^{2} / \mathrm{cow}$ ), fed with TMR consisting primarily of cereal or corn silage and concentrate food ad libitum, and had access to water ad libitum. The farms used a computerized dairy herd management system, including electronic milk meters, cow identification, and heat detection systems (Heatime; SCR, Netanya, Israel; or Afifarm; Afikim, Israel). Cows were milked 3 times per day, with an annual average milk yield ranging from approximately 11,500 to $13,000 \mathrm{~kg}$ per cow among farms (detailed farms information is provided in Supplemental Table S1). Clinical, reproduction, production, and management data were collected and recorded using dairy herd management software (NOA; Israeli Cattle Breeders Association, Caesarea, Israel). Postpartum metritis was diagnosed by the farm veterinarian using both vaginal and rectal examinations at 5 to $12 \mathrm{~d}$ after calving as we previ- ously described (Goshen and Shpigel, 2006; Sicsic et al., 2018). Briefly, vaginal discharge was evaluated by a gloved hand inserted through the vulva, the external cervical os was palpated, and the mucus was withdrawn manually for direct inspection. Cows presenting a purulent or mucopurulent vaginal discharge, and fetid smell combined with a large, thin-walled uterus excessively filled with gas or fluid were defined as postpartum metritis. Cows defined with metritis were treated with $5 \mathrm{~g}$ of intrauterine oxytetracycline (Oxtra, Fatro; or Alamycin, Norbrook Laboratories Ltd.) once a week until the presence of clear vaginal discharges. Urinary acetoacetic acid was measured (Ketostix, Bayer) at 5 to 12 DIM; cows with a concentration of $\geq 1.5 \mathrm{mmol}$ were considered having ketosis and were treated with 300 to $400 \mathrm{~g}$ of propylene glycol per os for 3 to $5 \mathrm{~d}$. Body condition score was assessed on a 5-point scale (Edmonson et al., 1989) at 40-60 DIM as part of the farms' veterinary routine.

Reproductive management was based on AI with thawed-frozen semen from proven sires, performed by highly trained technicians employed by Sion Ltd., Israel's leading company for dairy cow AI service. Cows were bred after the voluntary waiting period (VWP) on spontaneous estrus observed or detected by an automated activation monitor. In Israel, the economic management is based on milk quota for each farm; therefore, the calving plan over the year is cardinal to the farm management. As a result, the VWP is adjusted through the year as a management decision. Accordingly, the farms' VWP in the study was recorded (Supplemental Table S2, https://doi.org/10.5281/zenodo.5507320, Druker et al., 2021) and was included in our statistical models, as detailed below. During the study period, synchronization protocols were not used. The farmers and farm veterinarians were not aware of the clinical examination findings and endometrial cytology samples collected by the research team. Pregnancy diagnosis was performed by transrectal palpation of the reproductive tract at 45 to $50 \mathrm{~d}$ postinsemination. Reproductive data were collected until at least 180 DIM or until the date of culling, if earlier. The following reproductive performance parameters were recorded: interval from calving to pregnancy (open days) and first AI, the interval from first AI to pregnancy (waste days), pregnancy risk at 180 DIM, and first AI pregnancy risk.

\section{Endometrial Cytology Evaluation}

Two endometrial cytobrush cytology samples were collected from each cow at $35 \pm 5$ DIM (E35) and 65 \pm 5DIM (E65) and used to prepare cytological smears, as previously described by Kasimanickam et al. (2004). Briefly, before sampling, the vulva was cleaned by wipes 
containing chlorhexidine and $70 \%$ isopropanol (Pharma wipes, cat. no. 26350002; Dr. Fischer). After placing a clean plastic sleeve on the arm used for sampling, the vulva was lubricated. A sterile double-guarded endometrial cytobrush (cat. no. 17075/0010; Minitube) was placed through the vagina at the external cervical os. The same hand was then inserted rectally, and the cytobrush was guided through the cervix into the base of the uterine horn, where the brush was extracted from the protective sheaths. The uterine wall was pressed against the brush with some gentle pressure of the index finger through the rectum, and endometrial cytology was collected by rotating the brush 3 to 5 times. The brush was retracted into the protective sheaths, taken out of the vagina, and was immediately rolled on a clean glass microscope slide for cytological smears. All cytological smears were air-dried and stained by modified Wright's staining (Diff-Quick, cat no. 7543; Medi-Market). The PMN percentages were evaluated microscopically (magnification of 400×; AxioLab, Carl Zeiss) by a single experienced observer who was blinded to the slides' origin and the cows' status. For each stained slide, at least $300 \mathrm{PMN}$ and epithelial cells were counted and used to calculate the PMN proportion in the sample $[(\mathrm{PMN}$ cells $) /(\mathrm{PMN}+$ epithelial cells $)]$; red blood cells and other leukocytes, which were rare, were not included in the analysis.

\section{Statistical Analysis}

Individual cow data were exported from the NOA herd management software (Israeli Cattle Breeders Association) to Microsoft Excel (Microsoft Corporation). Statistical analysis was performed in $\mathrm{R}$ (version 3.5.1, $\mathrm{R}$ Foundation for Statistical Computing), considering the cow as the unit of interest. The PMN percentages results from the cytological evaluation were dichotomized at several threshold points (i.e., $1 \%, 2 \%$. $3 \%, 4 \%$, $5 \%, 6 \%, 7 \%, 8 \%, 9 \%, 10 \%, 15 \%$, and $20 \%$ ). Accordingly, all reproductive performance parameters were calculated for CEM-positive ( $\geq$ the $\% \mathrm{PMN}$ threshold) versus CEM-negative cows ( $<$ the \%PMN threshold) for each one of these thresholds. For data set assessment, descriptive statistics were conducted for the following outcomes: intervals from calving to pregnancy (open days) and first AI, the interval from first AI to pregnancy (waste days), pregnancy risk at 180 DIM, and first AI pregnancy risk. Cows were excluded from the analysis if cytology slides were not of diagnostic quality (e.g., hypocellular, unsuitable staining), or if they were not collected in the proper day range (E35, 30-40 DIM, $\mathrm{n}=27$ excluded; E65, 60-70 DIM, $\mathrm{n}=38$ excluded).

The CEM definition (positive versus negative) effects by the different thresholds on reproductive performance parameters were assessed for all the cows at E35 and E65 and independently for primiparous and for multiparous cows. In all analyses, the statistical models were controlled for the effect of metritis, retained fetal membranes (RFM), ketosis, and BCS at 40-60 DIM (van Straten et al., 2009) if the univariable test $P$ value was $\leq 0.2$ (i.e., chi-squared test for logistic regression model, and log-rank test for Cox's proportional hazards model). The effects of the farm and VWP (see Supplemental Table S2) were forced into the models. When all cows were analyzed together, the cow's parity (primiparous or multiparous status) was also forced into the models. Cox's proportional hazard models (Coxph function, Survival package, Therneau and Grambsch, 2000) were used to compare CEM-positive versus CEM-negative cows with regard to their intervals from calving to pregnancy (open days) and first AI, as well as the interval from first AI to pregnancy (waste days). The output in Cox's model was expressed as the hazard ratio (HR) of pregnancy per unit of time. The HR should be interpreted as the relative probability of conceiving for every day at risk in CEM-positive cows, as compared with CEM-negative cows (Dohoo et al., 2014). Cows were followed for $180 \mathrm{~d}$ from calving unless culled before. Cows that stopped being inseminated by decision, culled, or not pregnant/inseminated during this period were censored. Cows inseminated before the end of the declared VWP were excluded from the analysis (as detailed in Supplementary Table S2).

Pregnancy risk at 180 DIM and first service pregnancy risk in CEM-positive versus -negative cows were analyzed by Logistic regression models with (GLM function), with a binomial distribution and a logit link. Moreover, to evaluate the association of CEM with pregnancy, odds ratios (OR) were calculated by dividing the odds of pregnancy in the exposed (CEMpositive) group by the odds in the unexposed (CEMnegative) group, using the Logistic regression model's OR (Oddsratio package; Schratz, 2017). To select the most suitable PMN percent threshold for defining CEM for all cows, as well as independently for primiparous and for multiparous cows, we searched for the threshold that yielded the most remarkable absolute differences that were statistically significant between CEM-positive and -negative cows in as many of the parameters of reproductive performance; that is, the threshold that yielded the lowest $\mathrm{HR}$ in open days, calving to first AI interval, and waste days that were statistically significant between CEM-positive to CEM-negative cows, and that yielded the highest differences in first AI pregnancy risk and pregnancy risk at 180 DIM between CEM-positive and -negative cows. Following the selection of a PMN percentage threshold, we also compared the difference in the number of inseminations needed to 
achieve pregnancy among pregnant cows between CEM positive and negative using Wilcoxon rank-sum test.

In parallel, a receiver operator characteristics (ROC) curve (pROC package; Robin et al., 2011) was conducted, and the closest point to 0 on the $\mathrm{x}$-axis and 1 on the y-axis of the ROC curve was found, based on specificity and sensitivity for cows' pregnancy at 180 DIM and based on first AI pregnancy outcome (OptimalCutPoint package; López-Ratón et al., 2014). These ROC analyses were performed at E35 and E65 for all the cows (primiparous and multiparous) and independently for primiparous and multiparous cows. All the above-mentioned reproductive performance analyses (interval to first AI, open days, waste days, 180 DIM pregnancy risk, first service pregnancy risk) were also done according to the thresholds identified by the ROC curves.

Specificity, sensitivity, positive predictive value, and negative predictive value of each of the identified thresholds throughout the study (either by the comprehensive statistical approach or by using the ROC curves) were calculated for predicting at the third quartile of open days that was 180 DIM (open 180), and for predicting pregnancy from the first service. At all analyses, differences were considered significant at $P<0.05$ and a tendency at $0.05<P<0.1$. Unless otherwise noted, results are presented as mean \pm SEM.

\section{RESULTS}

Endometrial cytology results (\% PMN) and the corresponding calculated prevalence of CEM in each of the different thresholds are presented in Figure 1. From a total of 415 postpartum dairy cows enrolled in the study (269 multiparous; 146 primiparous), data were complete and analyzed from 388 cows at E35 (255 multiparous; 133 primiparous), and 377 cows at E65 (242 multiparous; 135 primiparous). Data regarding peripartum diseases in the primiparous and multiparous cows, as were available to us from the NOA herd management software, are presented in Supplemental Tables S3 and S4 (https://doi.org/10.5281/zenodo.5507320, Druker et al., 2021).

\section{Defining CEM by \%PMN in All Cows (Primiparous and Multiparous Together)}

Reproductive performance analyses of all cows, based on different \%PMN thresholds defining CEM at E35 and E65, are presented in Figures 2 and 3, respectively. From all examined thresholds at E35 in this analysis, a threshold of $\geq 4 \%$ PMN was associated with significantly lower reproductive performance in CEM-positive cows, as compared with CEM-negative cows, in most parameters (Figure 2), including longer interval from parturition to conception (open days: $\mathrm{HR}=0.70 ; 95 \%$ CI, 0.5165-0.9361; $P=0.0166)$, longer interval to first insemination $(\mathrm{HR}=0.69 ; 95 \% \mathrm{CI}, 0.5301-0.9041 ; P=$ $0.0057)$, lower first service pregnancy risk $(20.2 \%$ vs. $30.6 \%$; OR $=0.59 ; 95 \%$ CI, $0.345-1.003 ; P=0.0552)$, and lower pregnancy risk at $180 \mathrm{DIM}(50.7 \%$ vs. $62.5 \%$; $\mathrm{OR}=0.61 ; 95 \%$ CI, 0.395-0.956; $P=0.0310)$.

At E65 (Figure 3), when data from all cows were analyzed together, the same threshold of $4 \%$ PMN was selected, as it was associated with a longer interval from parturition to conception (open days: $\mathrm{HR}=0.71 ; 95 \%$ CI, 0.5137-0.9864; $P=0.0411$ ), increase in waste days $(\mathrm{HR}=0.76 ; 95 \% \mathrm{CI}, 0.5711-1.007 ; P=0.0562)$, more inseminations until conception $(2.9 \pm 0.2$ vs. $2.5 \pm 0.1$; $P=0.0469)$, as well as tendencies for lower first service pregnancy risk $(21.2 \%$ vs. $31.0 \%, \mathrm{OR}=0.58 ; 95 \% \mathrm{CI}$, $0.319-1.005 ; P=0.0580)$, and lower pregnancy risk at 180 DIM ( $52.9 \%$ vs. $61.3 \%$, OR $=0.67 ; 95 \%$ CI, 0.412 1.076; $P=0.0961)$ in CEM-positive versus -negative cows. The effect of parity in the analyses mentioned above, for data from all cows, was evident in the first AI pregnancy risk chi-squared univariable analysis $(P$ $=0.0141)$, and in the multivariable logistic regression model at E35 $(P=0.0635)$ and $\operatorname{E} 65(P=0.0106)$. Moreover, there were more multiparous cows with high percentages of PMN than primiparous cows (\%PMN $\geq 50 \% ; 28 / 255,11 \%$ vs. $6 / 133,4.5 \%$, respectively; $P$ $=0.0370)$. Accordingly, and based on our hypothesis, reproductive performance parameters using the different \% PMN thresholds were analyzed separately for primiparous and for multiparous cows, as detailed below.

Analysis of the ROC curve based on pregnancy risk at 180 DIM for all the cows revealed a threshold of $\geq 3.3 \%$ PMN for CEM diagnosis at E35; and the area under the ROC curve was 0.555 (95\% CI, 0.497-0.612). However, based on the first service pregnancy risk, the ROC curve analysis for all the cows at E35 revealed a threshold of $\geq 1.3 \%$ PMN for CEM diagnosis at E35; and the area under the ROC curve was 0.577 (95\% CI, 0.511-0.644).

Based on pregnancy risk at 180 DIM, analysis of the ROC curve for all cows revealed a threshold of $\geq 1 \%$ PMN for CEM diagnosis at E65; and the area under the ROC curve was 0.516 (95\% CI, 0.456-0.575). However, based on the first service pregnancy risk, the ROC curve analysis for all the cows revealed a threshold of $\geq 0.3 \%$ PMN for CEM diagnosis at E65; and the area under the ROC curve was 0.522 (95\% CI, 0.457-0.587).

The specificity, sensitivity, positive predictive values, and negative predictive values for the diagnosis of CEM in all cows (primiparous and multiparous together), based on the above-identified thresholds in the different analyses, are presented in Figure 4 (Figure 4C, E35: 4\% 
A

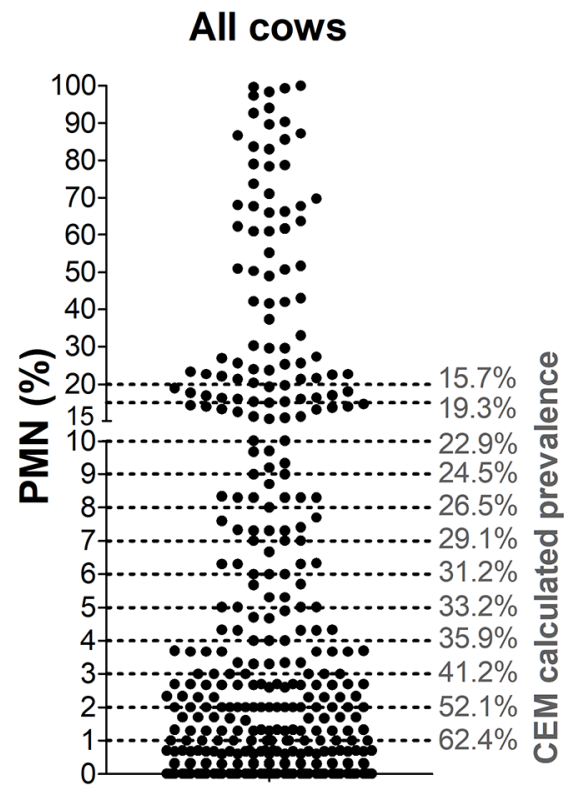

B

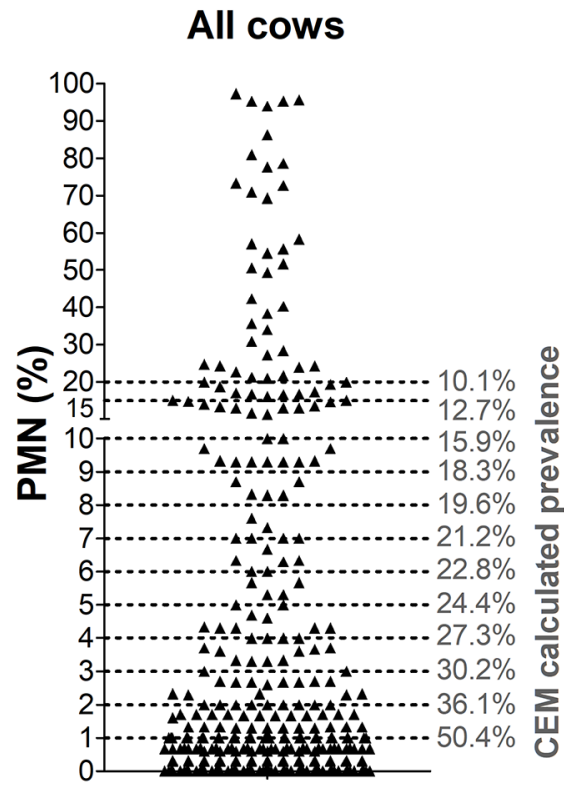

30-40 DIM

Primiparous

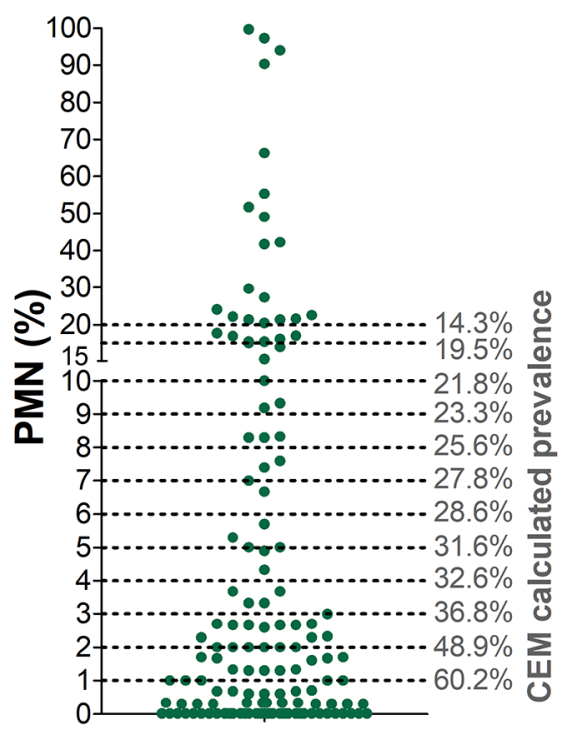

\section{0-70 DIM}

Primiparous

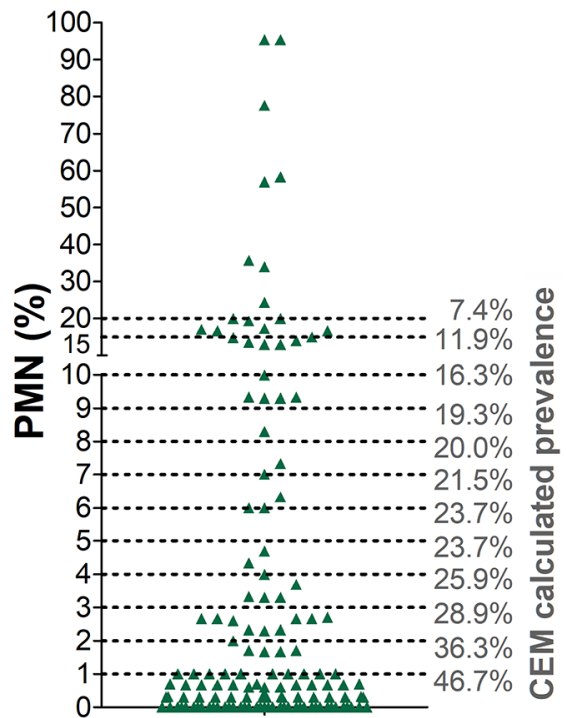

Multiparous

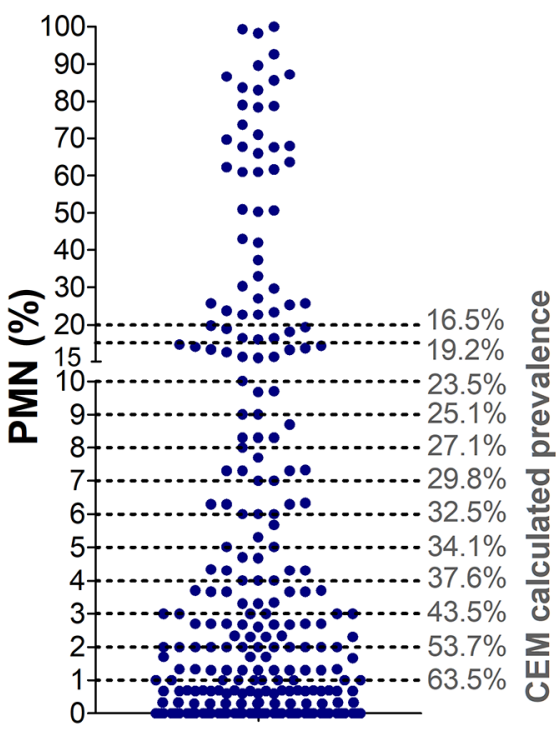

Multiparous

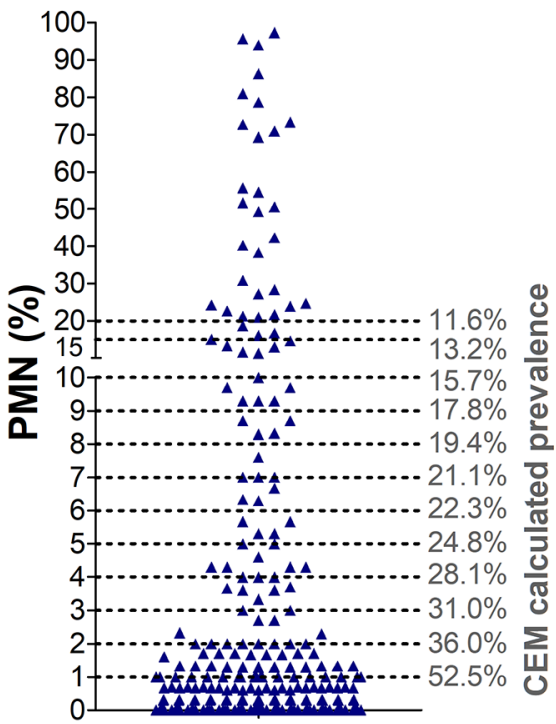

Figure 1. Distribution of \% PMN in endometrial cytology samples collected from Holstein dairy cows. Endometrial cytobrush cytology samples were collected from dairy cows, and the $\% \mathrm{PMN}$ were evaluated microscopically. Data are presented for all cows in the study $(\mathrm{n}=415$; left graphs, black dots), as well as separately for primiparous cows $(\mathrm{n}=146$; middle graphs, green dots) and multiparous cows $(\mathrm{n}=269$; right graphs, blue dots), at 30-40 DIM (A) and 60-70 DIM (B). Each dot represents the \%PMN in a sample of a single cow. Left y-axis: \%PMN in a cytological smear; right y-axis: calculated prevalence of cytological endometritis (CEM) using $\%$ PMN thresholds of $\geq 1-10 \%, \geq 15 \%$, and $\geq 20 \%$ PMN (cows with \% PMN $\geq$ threshold considered CEM positive). 
vs. $3.3 \%$ vs. $1.3 \%$; Figure 4 F, E65: $4 \%$ vs. $1 \%$ vs. $0.3 \%$ ). Comparisons of all CEM-negative versus CEM-positive cows' reproductive performance, based on these thresholds, indicated that when primiparous and multiparous are analyzed together, a threshold of $4 \%$ showed the most prominent differences between CEM-negative and CEM-positive cows, at both E35 and E65 (Figure 4).

\section{Defining CEM by \%PMN in Primiparous Cows}

Reproductive performance analyses of primiparous cows, based on different \%PMN thresholds defining CEM on E35 and E65, are presented in Figures 5 and 6, respectively. The results revealed that, in primiparous cows, a threshold of $\geq 7 \%$ PMN at E35 was associated with inferior reproductive performance in CEM-positive cows as compared with CEM-negative cows, in the vast majority of the analyzed parameters (Figure 5), including longer interval from parturition to conception (open days: $\mathrm{HR}=0.47 ; 95 \% \mathrm{CI}, 0.2349-0.9259 ; P=$ $0.0290)$, lower first service pregnancy risk $(20.0 \%$ vs. $38.7 \%$, OR $=0.35 ; 95 \%$ CI, $0.126-0.889 ; P=0.0353)$, lower pregnancy risk at 180 DIM (35.3\% vs. $62.2 \%$, OR $=0.34 ; 95 \%$ CI, 0.143-0.805; $P=0.0202)$, as well as a higher number of inseminations until conception was achieved among pregnant cows $(3.11 \pm 0.4$ vs. $2.36 \pm$
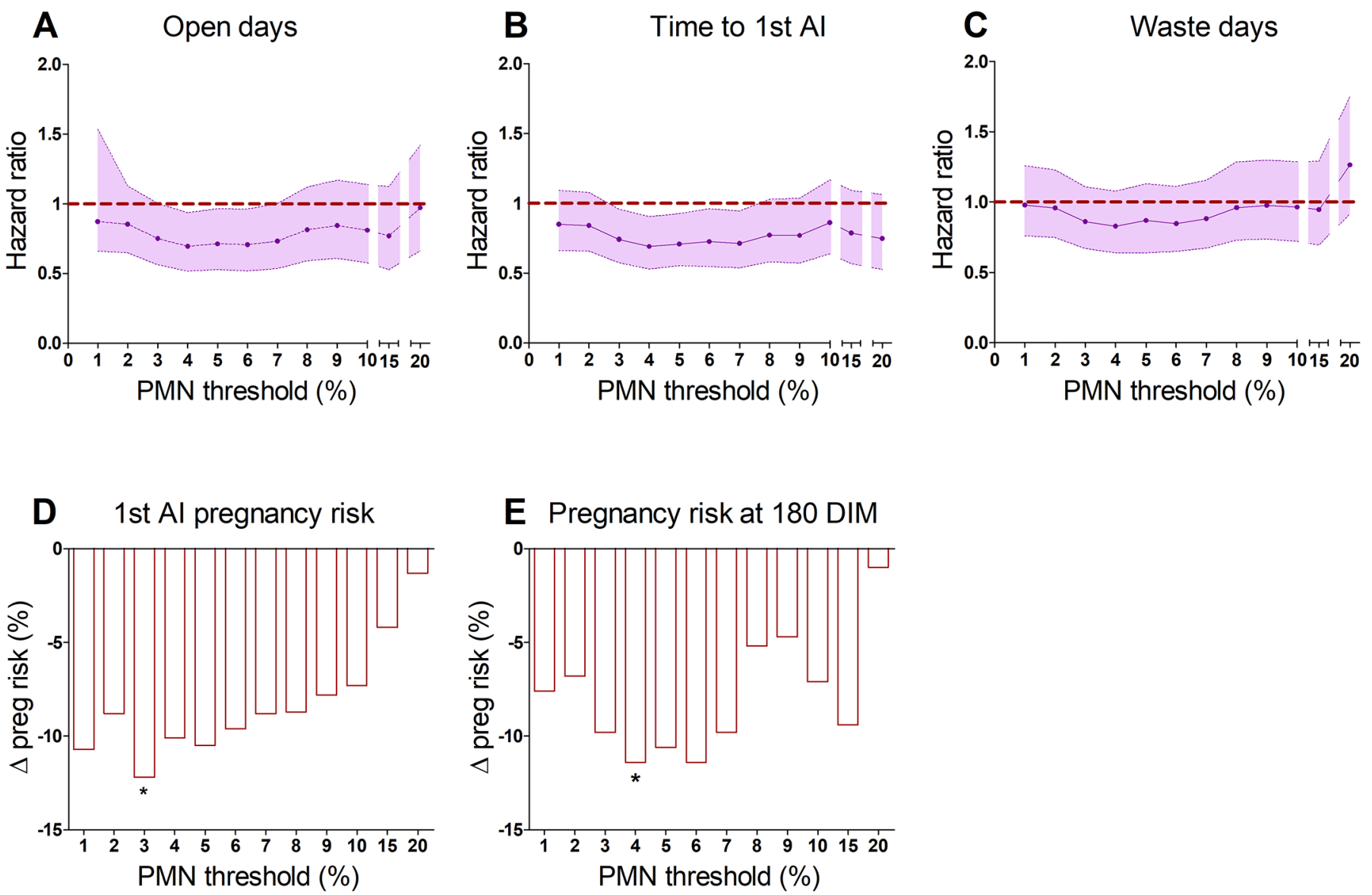

Figure 2. Reproductive performance analyses of dairy cows defined as cytological endometritis (CEM) positive versus negative by different \%PMN thresholds at 30-40 DIM. Cows were dichotomized at several \%PMN thresholds based on evaluation of endometrial cytobrush samples at 30-40 DIM, and accordingly, reproductive performance parameters were calculated and compared between CEM-positive ( $\geq$ the \%PMN threshold) versus CEM-negative cows (<the \% PMN threshold). Data are presented for all cows in the study (primiparous and multiparous together), and in all panels the x-axis represents the different thresholds. The results of Cox's proportional hazards models are presented for (A) open days [farm, parity, voluntary waiting period (VWP), and ketosis were the covariates in the model], (B) time to the first insemination (farm, parity, VWP, and metritis were the covariates in the model), and (C) waste days (farm, parity, VWP, and ketosis were the covariates in the model); in these planes, hazard ratio $(\mathrm{HR})=1$ is represented by the horizontal dotted line; values of HR significantly differ $(P<0.05)$ between CEMpositive and CEM-negative cows if the 95\% CI (purple area above and under the middle line) does not cross the dotted line. In panel D (first AI service pregnancy risk; farm, parity, VWP, and ketosis were the covariates in the model) and panel E (pregnancy risk at 180 DIM; farm, parity, VWP, ketosis, and BCS at 40-60 DIM were the covariates in the model), differences in pregnancy risks $[\Delta$ preg risk (\%); red bars $]$ in CEM-positive cows, as compared with CEM-negative cows (represented by the black horizontal line at Y $=0$ ), are shown (logistic regression models). In panels D and E, significant differences between CEM-positive and CEM-negative cows are marked with an asterisk $\left({ }^{*} P<0.05\right)$. 

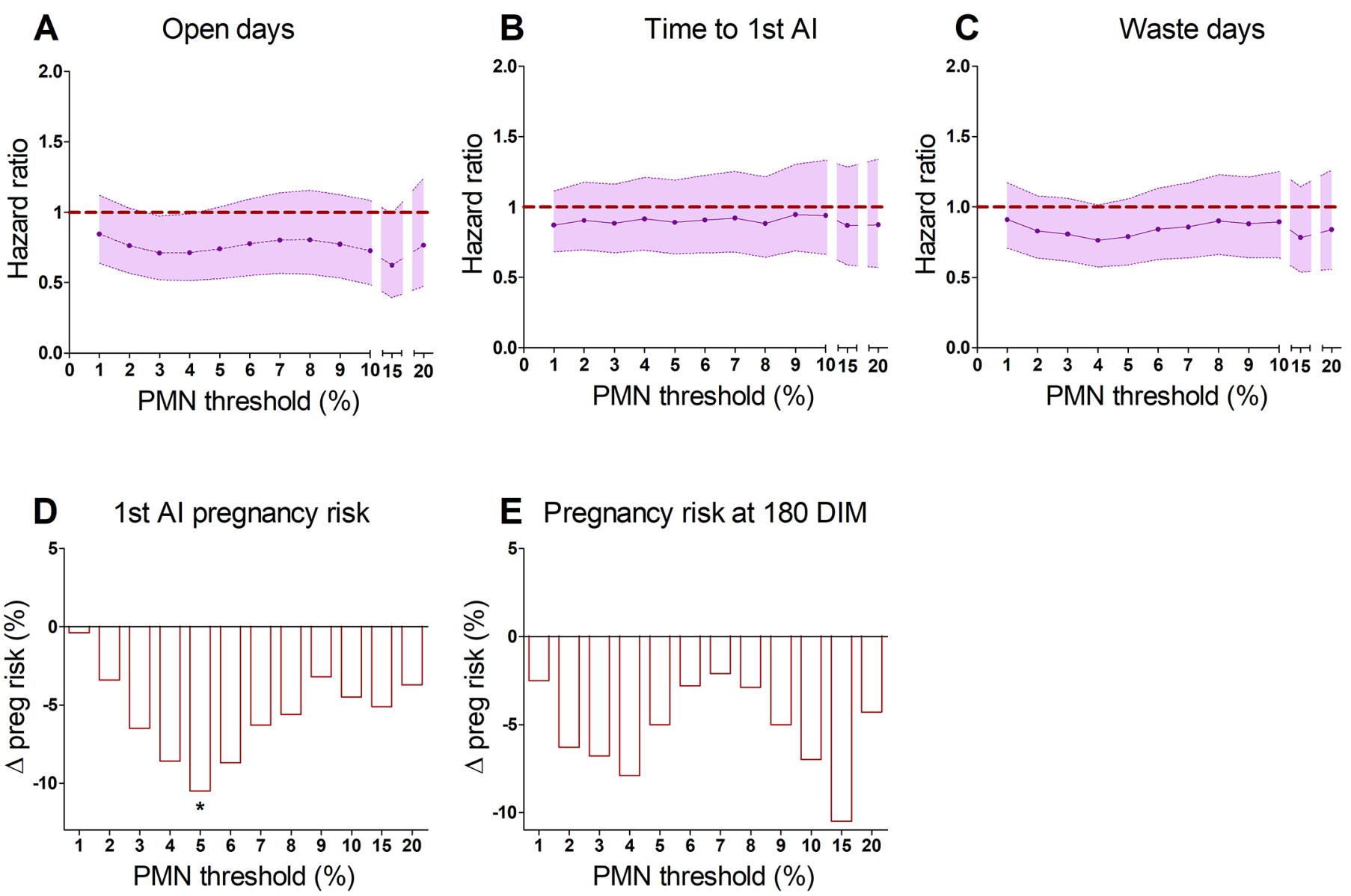

Figure 3. Reproductive performance analyses of dairy cows defined as cytological endometritis (CEM) positive versus negative by different \%PMN thresholds at 60-70 DIM. Cows were dichotomized at several \%PMN thresholds based on evaluation of endometrial cytobrush samples at 60-70 DIM, and accordingly, reproductive performance parameters were calculated and compared between CEM-positive ( $\geq$ the \%PMN threshold) versus CEM-negative cows (<the \%PMN threshold). Data are presented for all cows in the study (primiparous and multiparous together), and in all panels the x-axis represents the different thresholds. The results of Cox's proportional hazards models are presented for (A) open days [farm, parity, voluntary waiting period (VWP), and ketosis were the covariates in the model], (B) time to the first insemination (farm, parity, VWP, and metritis were the covariates in the model), and (C) waste days (farm, parity, VWP, and ketosis were the covariates in the model); in these planes, hazard ratio $(\mathrm{HR})=1$ is represented by the horizontal dotted line; values of HR significantly differ $(P<0.05)$ between CEMpositive and CEM-negative cows if the 95\% CI (purple area above and under the middle line) does not cross the dotted line. In panel D (first AI service pregnancy risk; farm, parity, VWP, and ketosis were the covariates in the model) and panel E (pregnancy risk at 180 DIM; farm, parity, VWP, ketosis, and BCS at 40-60 DIM were the covariates in the model), differences in pregnancy risks [ $\Delta$ preg risk (\%); red bars] in CEM-positive cows, as compared with CEM-negative cows (represented by the black horizontal line at $\mathrm{Y}=0$ ), are shown (logistic regression models). In panels D and E, significant differences between CEM-positive and CEM-negative cows are marked with an asterisk $\left({ }^{*} P<0.05\right)$.

$0.2 ; P=0.0551)$. However, at E65, none of the PMN thresholds were associated with a significant reduction in reproductive performance in primiparous cows defined as CEM positive compared with CEM negative (Figure 6).

The ROC curve analysis for primiparous cows at E35 based on pregnancy risk at 180 DIM revealed a threshold of $\geq 1.3 \%$ PMN for CEM diagnosis; and the area under the ROC curve was 0.631 (95\% CI, 0.536-0.726). Analysis of the ROC curve for primiparous cows based on the first service pregnancy risk revealed the same threshold of $\geq 1.3 \%$ PMN for CEM diagnosis at E35; and the area under the ROC curve was 0.613 (95\% CI, 0.511-0.715).

Based on the pregnancy risk at 180 DIM, the ROC curve analysis for primiparous cows revealed a threshold of $\geq 2 \%$ PMN for CEM diagnosis at E65; and the area under the ROC curve was 0.422 (95\% CI, 0.325-0.520). The specificity, sensitivity, positive predicted value, and negative predicted value, based on pregnancy risk at 180 DIM as an outcome, were $61.5 \%, 33.3 \%, 38.8 \%$, and $55.8 \%$, respectively. However, based on the first service pregnancy risk, the ROC curve analysis for primiparous cows revealed a threshold of $\geq 0.3 \%$ PMN for 


\section{CEM diagnosis in all cows 30-40 DIM}
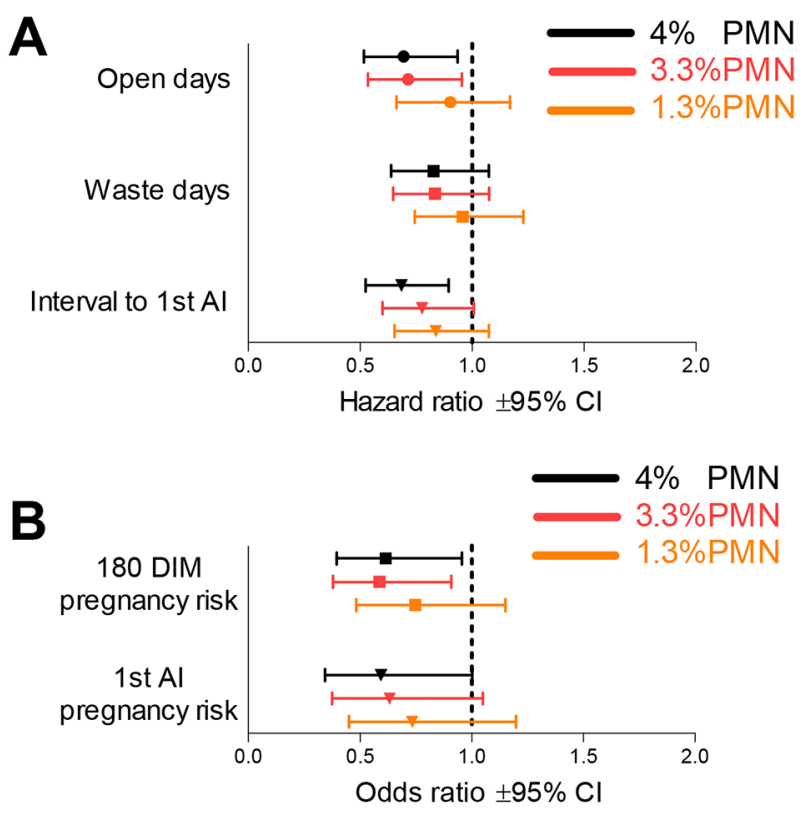

\begin{tabular}{|c|c|c|c|}
\hline & $4 \% \mathrm{PMN}$ & 1.3\%PMN & $3.3 \% \mathrm{PMN}$ \\
\hline Prevalence & $35.9 \%$ & $62.4 \%$ & $39.4 \%$ \\
\hline \multicolumn{4}{|c|}{ Parameters based on 180 DIM pregnancy risk } \\
\hline Specificity & $68.6 \%$ & $45.6 \%$ & $65.5 \%$ \\
\hline Sensitivity & $42.2 \%$ & $64.2 \%$ & $46.3 \%$ \\
\hline PPV & $48.9 \%$ & $54.2 \%$ & $49.0 \%$ \\
\hline NPV & $62.5 \%$ & $64.0 \%$ & $63.0 \%$ \\
\hline
\end{tabular}

Parameters based on 1st Al pregnancy risk

\begin{tabular}{llll} 
Specificity & $73.5 \%$ & $52.0 \%$ & $70.4 \%$ \\
Sensitivity & $38.3 \%$ & $60.8 \%$ & $42.3 \%$ \\
PPV & $79.5 \%$ & $77.4 \%$ & $79.4 \%$ \\
NPV & $30.6 \%$ & $32.9 \%$ & $31.1 \%$ \\
\hline
\end{tabular}

\section{CEM diagnosis in all cows 60-70 DIM}
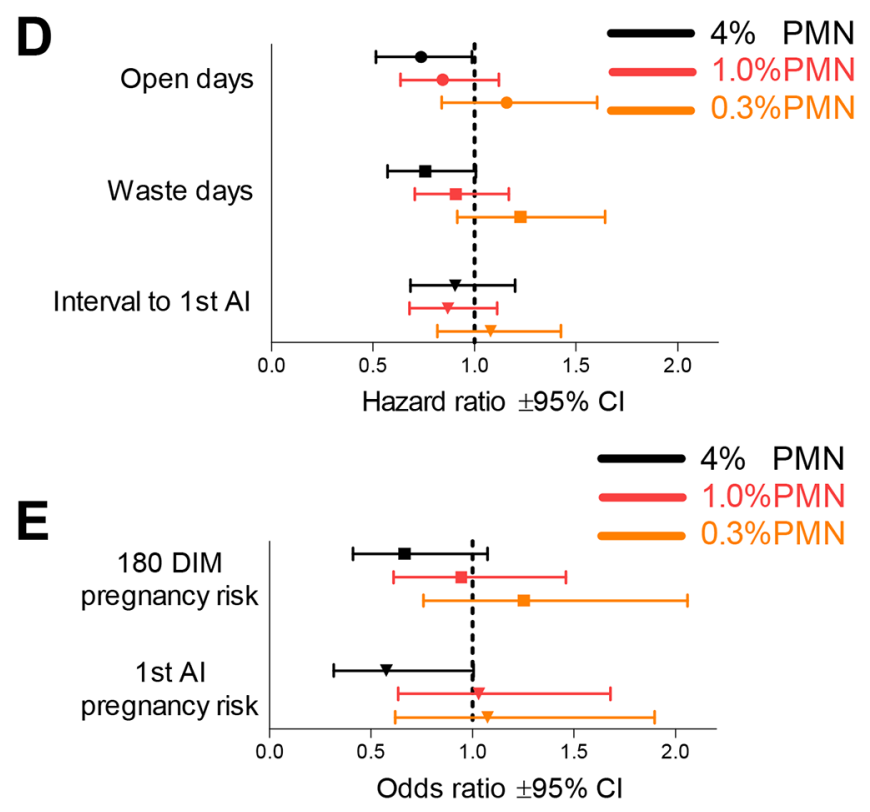

\begin{tabular}{cccc}
\hline & $\mathbf{4} \% \mathrm{PMN}$ & $0.3 \% \mathrm{PMN}$ & $1 \% \mathrm{PMN}$ \\
\hline Prevalence & $27.3 \%$ & $74.5 \%$ & $50.4 \%$
\end{tabular}

Parameters based on 180 DIM pregnancy risk

$\begin{array}{llll}\text { Specificity } & 75.3 \% & 24.1 \% & 50.7 \% \\ \text { Sensitivity } & 31.2 \% & 72.7 \% & 51.9 \% \\ \text { PPV } & 46.6 \% & 39.9 \% & 42.1 \% \\ \text { NPV } & 61.3 \% & 56.2 \% & 60.4 \%\end{array}$

Parameters based on 1st Al pregnancy risk

$\begin{array}{llll}\text { Specificity } & 79.2 \% & 25.7 \% & 49.5 \% \\ \text { Sensitivity } & 30.2 \% & 74.1 \% & 51.0 \% \\ \text { PPV } & 78.6 \% & 71.6 \% & 71.8 \% \\ \text { NPV } & 31.0 \% & 28.3 \% & 28.6 \%\end{array}$

Figure 4. Implications of cytological endometritis (CEM) diagnosis in dairy cows based on \%PMN threshold values identified by different statistical models. Endometrial cytobrush samples were collected from dairy cows $(\mathrm{n}=415)$ at 30-40 DIM and 60-70 DIM, and the \%PMN were evaluated microscopically. Different \% PMN thresholds were identified based on different statistical models [black, thresholds obtained from a combined evaluation of multiple reproductive performance parameters; red, thresholds obtained from receiver operator characteristic (ROC) analyses of 180 DIM pregnancy risk; orange, thresholds obtained from ROC analyses of first AI service pregnancy risk]. According to these thresholds, comparisons are presented for CEM-positive versus CEM-negative cows, regarding reproductive performance parameters (30-40 DIM, panels A and B; 60-70 DIM, panels D and E). In addition, for each of the thresholds, the calculated CEM prevalence, as well as the CEM diagnosis specificity, sensitivity, positive predictive values (PPV), and negative predictive values (NPV), are presented in panels C (30-40 DIM) and F (60-70 DIM), as calculated based on 180 DIM pregnancy risk and based on first AI pregnancy risk. Data in this figure are presented for all cows (primiparous and multiparous together). In panels A, B, D, and E, values of hazard ratios (A, D) and odds ratios (B, E) significantly differ $(P<0.05)$ between CEM-positive and CEM-negative cows if the $95 \%$ CI (whiskers) does not cross the vertical dotted line. According to the data presented in this figure, when primiparous and multiparous are analyzed together, a threshold of $4 \%$ PMN showed the most prominent differences between CEM-negative and CEM-positive cows, at both 30-40 DIM and 60-70 DIM, with higher specificity as compared with the other tested thresholds. 

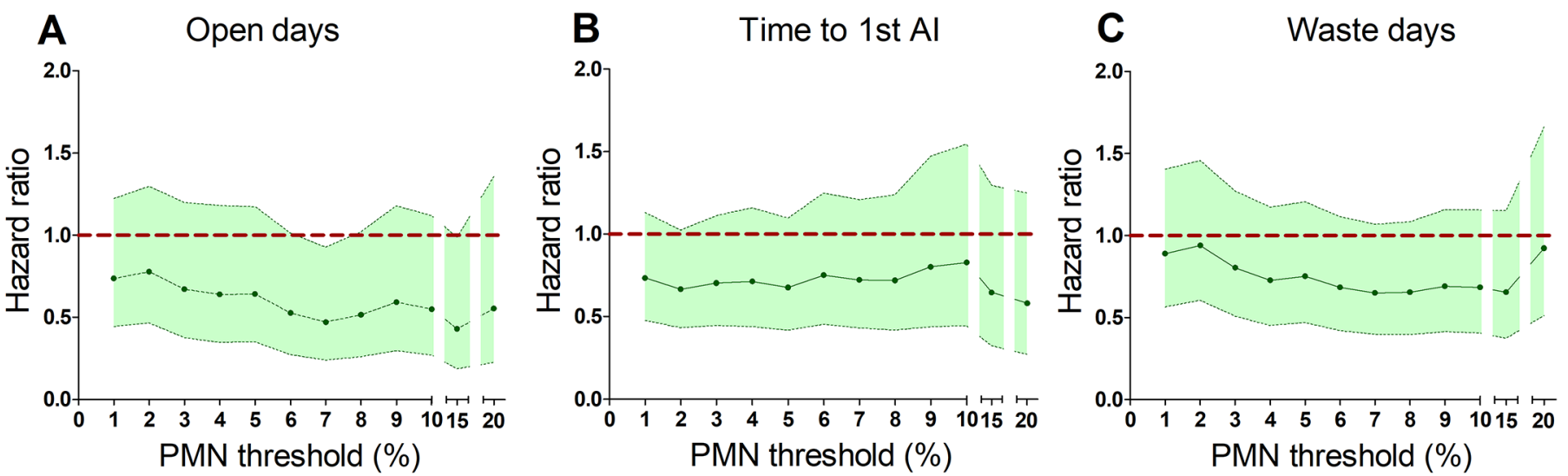

D $\quad$ 1st Al pregnancy risk

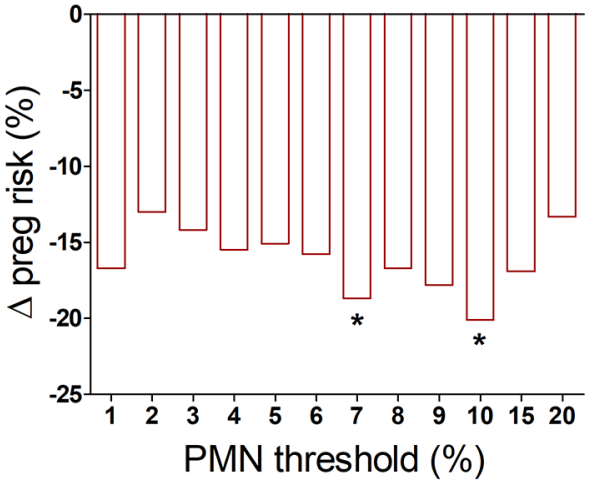

E Pregnancy risk at $180 \mathrm{DIM}$

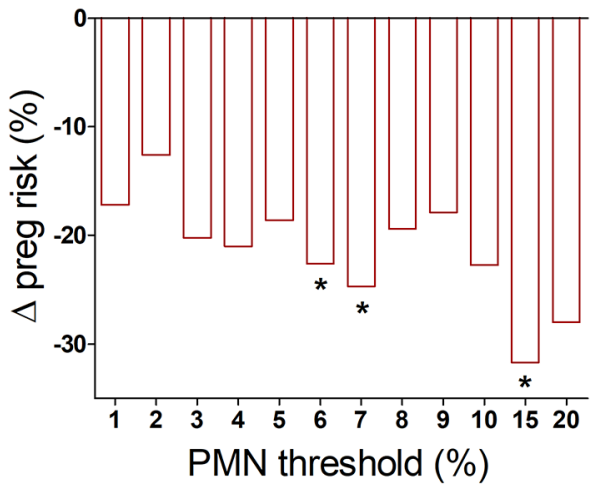

Figure 5. Reproductive performance analyses of primiparous dairy cows defined as cytological endometritis (CEM) positive versus negative by different \%PMN thresholds at 30-40 DIM. Primiparous cows were dichotomized at several \%PMN thresholds based on evaluation of endometrial cytobrush samples at 30-40 DIM, and accordingly, reproductive performance parameters were calculated and compared between CEM-positive ( $\geq$ the \%PMN threshold) versus CEM-negative cows ( $<$ the \%PMN threshold). In this figure, data are presented only for the primiparous cows included in the study $(\mathrm{n}=146)$, and in all panels the $\mathrm{x}$-axis represents the different thresholds. The results of Cox's proportional hazards models are presented for (A) open days [farm, voluntary waiting period (VWP), ketosis, and BCS at 40-60 DIM were the covariates in the model], (B) time to the first insemination (farm, VWP, ketosis, and metritis were the covariates in the model), and (C) waste days (farm and VWP were the covariates in the model); in these planes, hazard ratio $=1$ is represented by the horizontal dotted line; values of hazard ratio significantly differ $(P<0.05)$ between CEM-positive and CEM-negative cows if the 95\% CI (green area above and under the middle line) does not cross the dotted line. In panel D (first AI service pregnancy risk; farm and VWP were the covariates in the model) and panel E (pregnancy risk at 180 DIM: farm, VWP, ketosis, and BCS at 40-60 DIM were the covariates in the model), differences in pregnancy risks $[\Delta$ preg risk (\%); red bars] in CEM-positive cows, as compared with CEM-negative cows (represented by the black horizontal line at $\mathrm{Y}=0$ ), are shown (logistic regression models). In panels D and E, significant differences between CEM-positive and CEM-negative cows are marked with an asterisk $(* P$ $<0.05)$.

CEM diagnosis at E65; and the area under the ROC curve was $0.433(95 \% \mathrm{CI}, 0.331-0.534)$. The specificity, sensitivity, positive predicted value, and negative predicted value, based on pregnancy following the first insemination as an outcome, were $35.4 \%, 59.0 \%, 61.2 \%$, and $33.3 \%$, respectively.

The specificity, sensitivity, positive predictive values, and negative predictive values for the diagnosis of CEM in primiparous cows at E35, based on all aboveidentified thresholds in the different analyses, including the threshold identified for all cows, are presented in Figure 7 (Figure 7C, $4 \%$ vs. $1.3 \%$ vs. 1.3 vs. $7 \%$ ). Com- parisons of reproductive performance of primiparous CEM-negative versus CEM-positive cows at E35, based on these thresholds, indicated that a threshold of $7 \%$ showed the most prominent differences (Figure 7A-B). Nevertheless, based on these results, CEM diagnosis in primiparous cows was not beneficial at E65.

\section{Defining CEM by \%PMN in Multiparous Cows}

Reproductive performance analyses of multiparous cows, based on different \%PMN thresholds defining CEM on E35 and E65, are presented in Figures 8 and 
9 , respectively. In contrast to the results of primiparous cows at E35, in multiparous cows (Figure 8), none of the \% PMN thresholds were associated with reduced reproductive performance in cows defined as CEM positive, compared with CEM-negative cows. However, at E65 (Figure 9), multiparous cows defined as CEM positive using a threshold of $\geq 4 \%$ had poorer reproductive performance, in the majority of parameters, including longer interval from calving to conception (open days: $\mathrm{HR}=0.54 ; 95 \% \mathrm{CI}, 0.3544-0.8135 ; P=$ 0.0033 ) and from first insemination (waste days: HR = $0.57 ; 95 \%$ CI, 0.3951-0.8171; $P=0.0023$ ), lower first service pregnancy risk $(12.3 \%$ vs. $28.0 \%$; $\mathrm{OR}=0.33$;
95\% CI, 0.130-0.733; $P=0.0101)$, lower pregnancy risk at 180 DIM ( $46.4 \%$ vs. $65.3 \%$. OR $=0.41 ; 95 \% \mathrm{CI}$, $0.227-0.743 ; P=0.0034)$, as well as a higher number of inseminations until conception was achieved among pregnant cows $(3.2 \pm 0.3$ vs. $2.5 \pm 0.1 ; P=0.0107)$.

Analysis of the ROC curve for multiparous cows based on pregnancy risk at 180 DIM revealed a threshold of $\geq 3.33 \%$ PMN for CEM diagnosis at E35; and the area under the ROC curve was 0.516 (95\% CI, $0.444-0.588)$. The specificity, sensitivity, positive predicted value, and negative predicted value, based on pregnancy risk at 180 DIM as an outcome, were $63.2 \%$, $45.6 \%, 45.6 \%$, and $63.2 \%$, respectively. Based on the
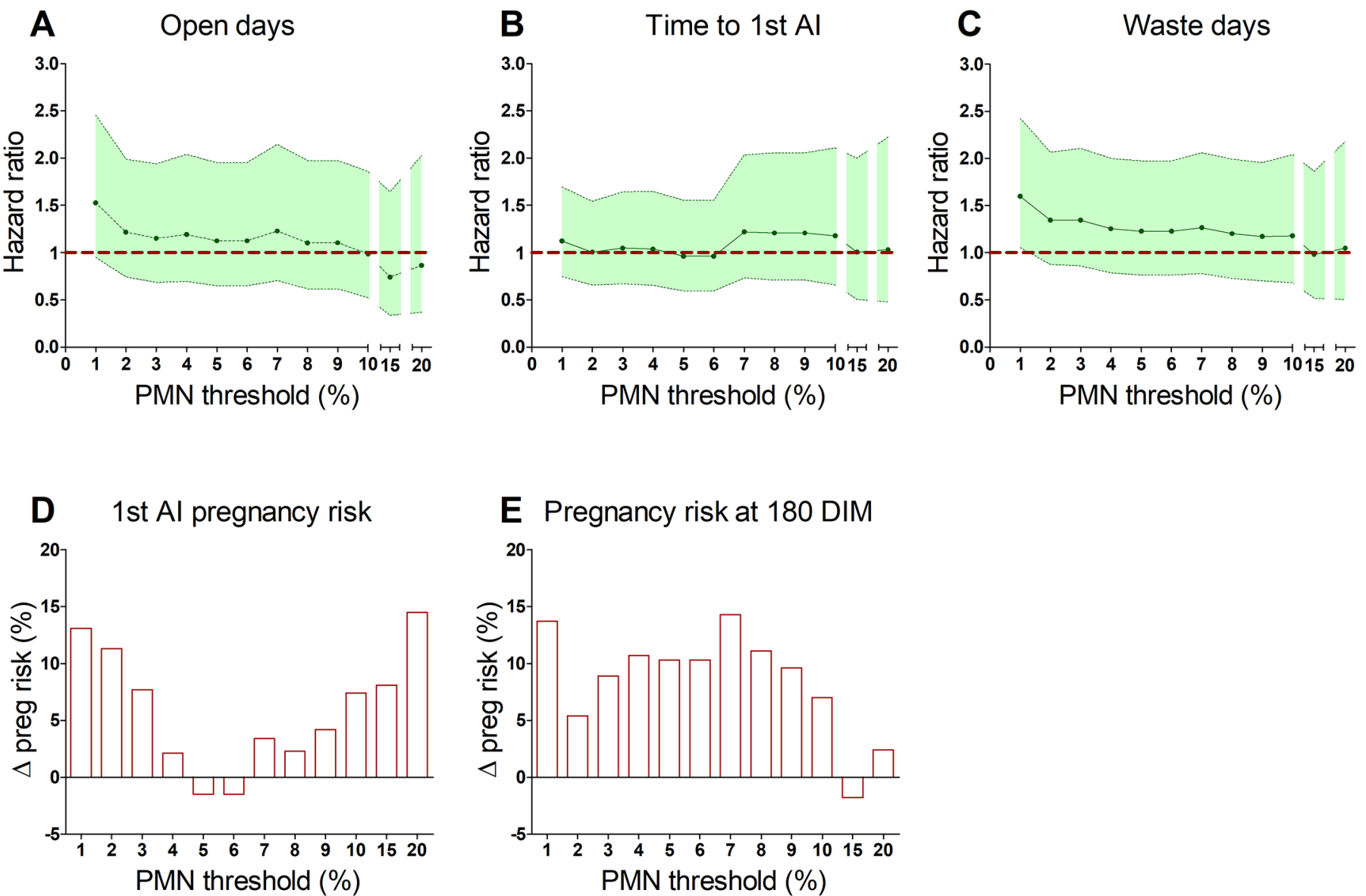

Figure 6. Reproductive performance analyses of primiparous dairy cows defined as cytological endometritis (CEM) positive versus negative by different \%PMN thresholds at 60-70 DIM. Primiparous cows were dichotomized at several \%PMN thresholds based on evaluation of endometrial cytobrush samples at 60-70 DIM, and accordingly, reproductive performance parameters were calculated and compared between CEM-positive ( $\geq$ the \%PMN threshold) versus CEM-negative cows ( $<$ the \%PMN threshold). In this figure, data are presented only for the primiparous cows included in the study $(\mathrm{n}=146)$, and in all panels the $\mathrm{x}$-axis represents the different thresholds. The results of Cox's proportional hazards models are presented for (A) open days [farm, voluntary waiting period (VWP), ketosis, and BCS at 40-60 DIM were the covariates in the model], (B) time to the first insemination (farm, VWP, ketosis, and metritis were the covariates in the model), and (C) waste days (farm and VWP were the covariates in the model); in these planes, hazard ratio $=1$ is represented by the horizontal dotted line; values of hazard ratio significantly differ $(P<0.05)$ between CEM-positive and CEM-negative cows if the 95\% CI (green area above and under the middle line) does not cross the dotted line. In panel D (first AI service pregnancy risk; farm and VWP were the covariates in the model) and panel E (pregnancy risk at 180 DIM: farm, VWP, ketosis and BCS at 40-60 DIM were the covariates in the model), differences in pregnancy risks $[\Delta$ preg risk (\%); red bars] in CEM-positive cows, as compared with CEM-negative cows (represented by the black horizontal line at $\mathrm{Y}=0$ ), are shown (logistic regression models). 


\section{CEM diagnosis in primiparous cows (30-40 DIM)}
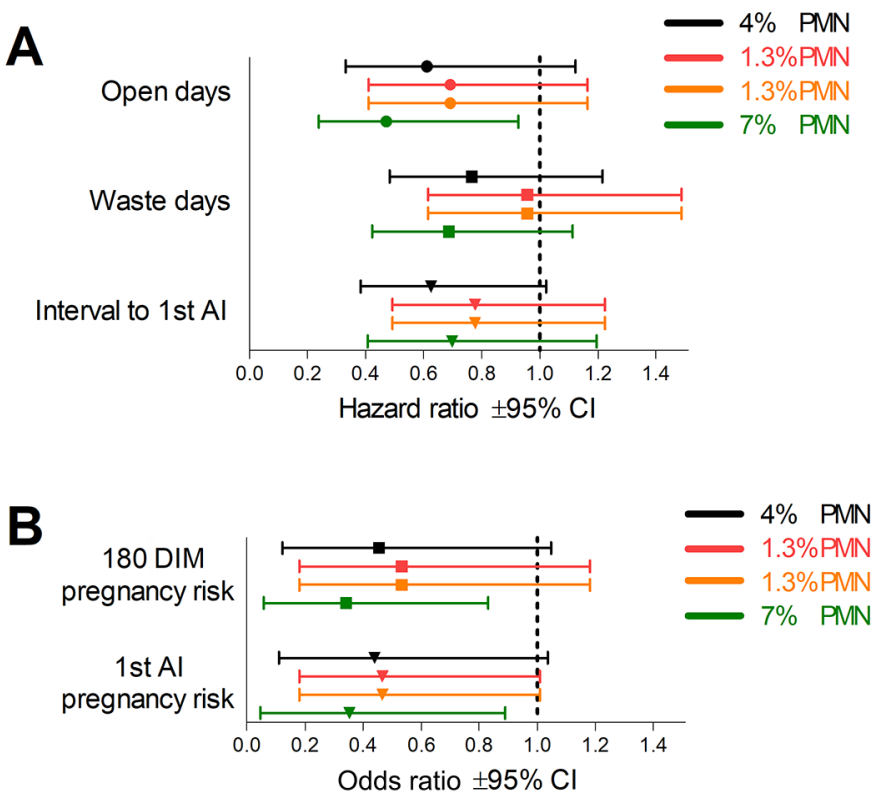

\begin{tabular}{|c|c|c|c|c|}
\hline & $4 \% \mathrm{PMN}$ & $1.3 \% \mathrm{PMN}$ & $1.3 \% \mathrm{PMN}$ & $7 \% \mathrm{PMN}$ \\
\hline Prevalence & $32.6 \%$ & $56.4 \%$ & $56.4 \%$ & $27.8 \%$ \\
\hline \multicolumn{5}{|c|}{ Parameters based on 180 DIM pregnancy risk } \\
\hline Specificity & $75.7 \%$ & $52.7 \%$ & $52.7 \%$ & $81.1 \%$ \\
\hline Sensitivity & $43.1 \%$ & $67.8 \%$ & $67.8 \%$ & $39.0 \%$ \\
\hline PPV & $58.1 \%$ & $53.3 \%$ & $53.3 \%$ & $62.2 \%$ \\
\hline NPV & $62.9 \%$ & $67.2 \%$ & $67.2 \%$ & $62.5 \%$ \\
\hline
\end{tabular}

\begin{tabular}{lllll}
\multicolumn{5}{c}{ Parameters based on 1st Al pregnancy risk } \\
Specificity & $79.1 \%$ & $58.1 \%$ & $58.1 \%$ & $83.7 \%$ \\
Sensitivity & $35.7 \%$ & $61.2 \%$ & $61.2 \%$ & $32.9 \%$ \\
PPV & $76.9 \%$ & $74.3 \%$ & $74.3 \%$ & $80.0 \%$ \\
NPV & $38.6 \%$ & $43.1 \%$ & $43.1 \%$ & $38.7 \%$ \\
\hline
\end{tabular}

\section{CEM diagnosis in multiparous cows (60-70 DIM)}
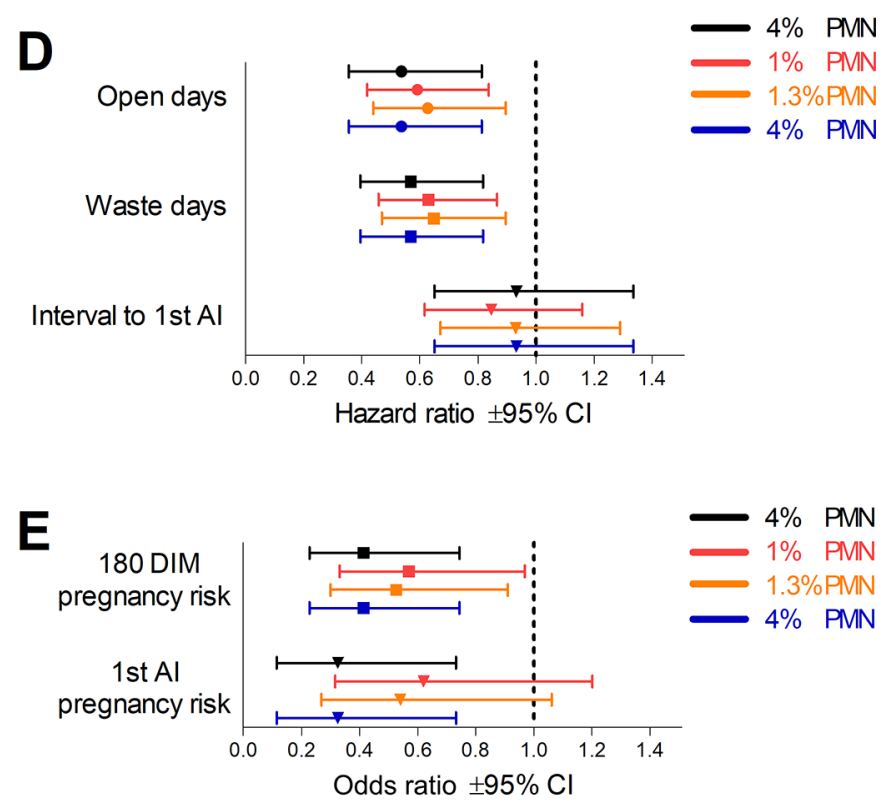

\begin{tabular}{|c|c|c|c|c|}
\hline & $4 \% \mathrm{PMN}$ & $1.3 \% \mathrm{PMN}$ & $1 \% \mathrm{PMN}$ & $4 \% \mathrm{PMN}$ \\
\hline Prevalence & $28.1 \%$ & $44.6 \%$ & $52.5 \%$ & $28.1 \%$ \\
\hline \multicolumn{5}{|c|}{ Parameters based on 180 DIM pregnancy risk } \\
\hline Specificity & $77.9 \%$ & $59.3 \%$ & $52.4 \%$ & $77.9 \%$ \\
\hline Sensitivity & $37.1 \%$ & $50.5 \%$ & $59.8 \%$ & $37.1 \%$ \\
\hline PPV & $52.9 \%$ & $45.4 \%$ & $45.7 \%$ & $52.9 \%$ \\
\hline NPV & $64.9 \%$ & $64.2 \%$ & $66.1 \%$ & $64.9 \%$ \\
\hline \multicolumn{5}{|c|}{ Parameters based on 1st Al pregnancy risk } \\
\hline Specificity & $84.9 \%$ & $62.3 \%$ & $54.7 \%$ & $84.9 \%$ \\
\hline Sensitivity & $34.6 \%$ & $47.1 \%$ & $55.2 \%$ & $34.6 \%$ \\
\hline PPV & $87.5 \%$ & $80.2 \%$ & $79.8 \%$ & $87.5 \%$ \\
\hline NPV & $28.0 \%$ & $26.6 \%$ & $27.4 \%$ & $28.0 \%$ \\
\hline
\end{tabular}

Figure 7. Implications of cytological endometritis (CEM) diagnosis in primiparous (30-40 DIM) and multiparous (60-70 DIM) dairy cows based on \% PMN threshold values identified by different statistical models. Endometrial cytobrush samples were collected from dairy cows $(\mathrm{n}=$ 415) at 30-40 DIM and 60-70 DIM, and the percentages of polymorphonuclear cells (\%PMN) were evaluated microscopically. Different \% PMN thresholds were identified based on different statistical models [black, thresholds obtained from analyses of all cows together, as illustrated in Figures 2, 3, and 4, i.e., 4\%; red, thresholds obtained from receiver operator characteristic (ROC) analyses of 180 DIM pregnancy risk; orange, thresholds obtained from ROC analyses of first AI service pregnancy risk; green/blue, thresholds obtained from a combined evaluation of multiple reproductive performance parameters; the last 3 types of thresholds were identified for primiparous and multiparous separately]. According to these thresholds, comparisons are presented for CEM-positive versus CEM-negative cows. In panels A-C, implications of CEM diagnosis in primiparous cows, at 30-40 DIM, are presented, whereas in panels D-F, data regarding CEM diagnosis in multiparous cows, at 60-70 DIM, are presented. Reproductive performance parameters are presented in panels A, B, D, and E. In these panels, values of hazard ratios (A, D) and odds ratios $(\mathrm{B}, \mathrm{E})$ significantly differ $(P<0.05)$ between CEM-positive and CEM-negative cows if the $95 \%$ CI (whiskers) does not cross the vertical dotted line. In addition, for each of the thresholds, the calculated CEM prevalence, as well as the CEM diagnosis specificity, sensitivity, positive predictive values (PPV), and negative predictive values (NPV), are presented in panels C (primiparous, 30-40 DIM) and F (multiparous, 60-70 DIM), as calculated based on 180 DIM pregnancy risk and based on first AI pregnancy risk. Based on the data presented, optimal diagnosis of CEM should be performed by different criteria in primiparous and multiparous cows: in primiparous cows at 30-40 DIM, using a threshold of $\geq 7 \%$ PMN, and in multiparous cows at 60-70 DIM, using a threshold of $\geq 4 \%$ PMN. 
first service pregnancy risk, the ROC curve analysis for multiparous cows revealed a threshold of $\geq 3 \%$ PMN for CEM diagnosis at E35; and the area under the ROC curve was 0.546 (95\% CI, 0.457-0.635). The specificity, sensitivity, positive predicted value, and negative predicted value, based on pregnancy following the first insemination as an outcome, were $67.3 \%, 46.7 \%, 82.4 \%$, and $27.8 \%$, respectively.

The ROC analysis based on pregnancy risk at 180 DIM, at E65 for multiparous cows, revealed a threshold of $\geq 1 \% \mathrm{PMN}$; and the area under the ROC curve was 0.572 (95\% CI, 0.498-0.646). Based on the first service pregnancy risk, the ROC curve analysis for multiparous cows revealed a threshold of $\geq 1.3 \%$ PMN for CEM diagnosis at E65; and the area under the ROC curve was 0.584 (95\% CI, 0.500-0.667).

The specificity, sensitivity, positive predictive values, and negative predictive values for the diagnosis of CEM in multiparous cows at E65, based on all aboveidentified thresholds in the different analyses, including the threshold identified for all cows, are presented in Figure 7 (Figure 7 F, $4 \%$ vs. $1.3 \%$ vs. $1 \%$ vs. $4 \%$ ). Comparisons of reproductive performance of multiparous CEM-negative versus CEM-positive cows at E65, based on these thresholds, indicated that a threshold of $4 \%$ showed the most prominent differences (Figure 7D-E).
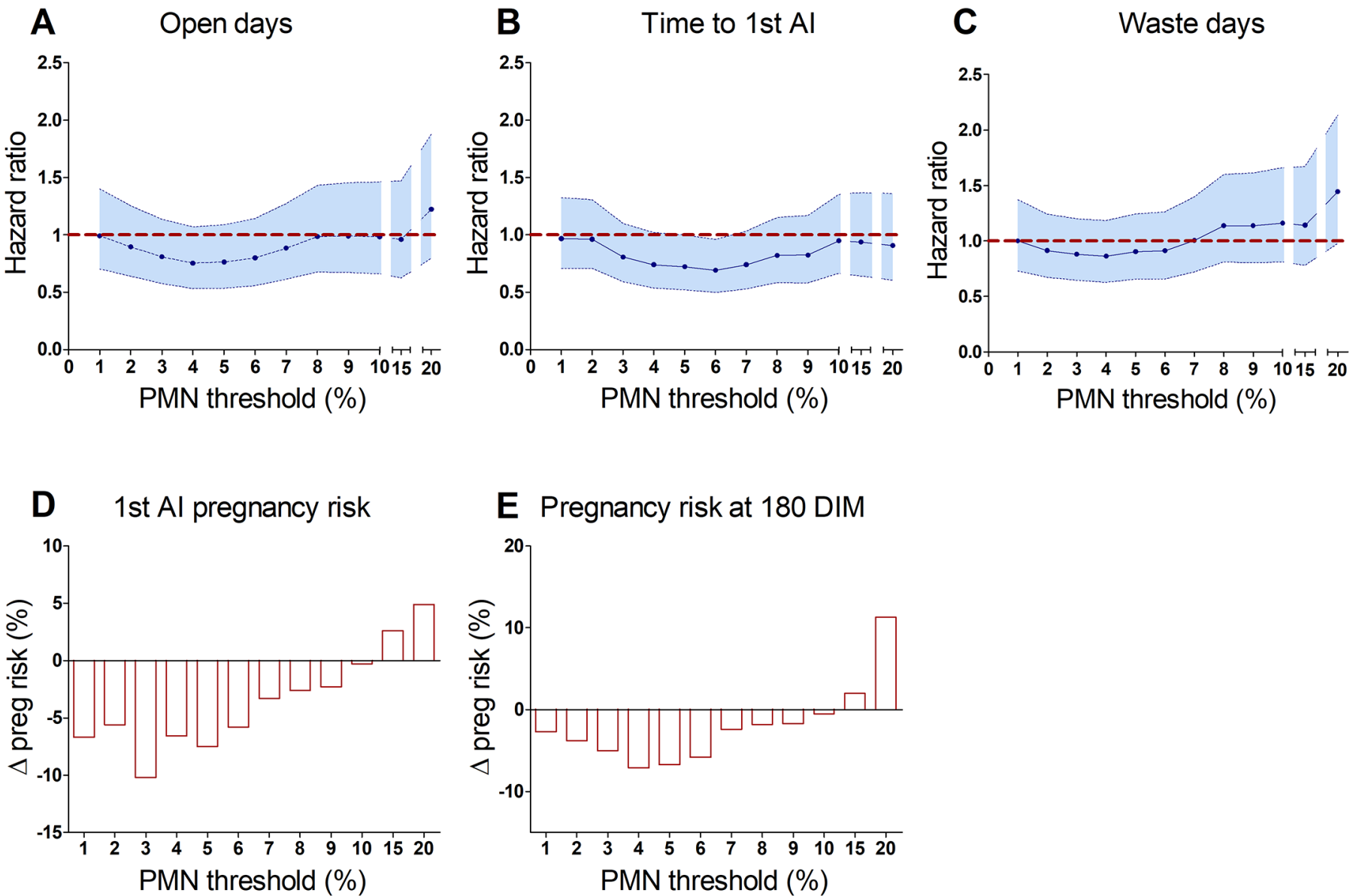

Figure 8. Reproductive performance analyses of multiparous dairy cows defined as cytological endometritis (CEM) positive versus negative by different \%PMN thresholds at 30-40 DIM. Multiparous cows were dichotomized at several \% PMN thresholds based on evaluation of endometrial cytobrush samples at 30-40 DIM, and accordingly, reproductive performance parameters were calculated and compared between CEM-positive ( $\geq$ the \%PMN threshold) versus CEM-negative cows ( $<$ the \%PMN threshold). In this figure, data are presented only for the multiparous cows included in the study $(\mathrm{n}=296)$, and in all panels the $\mathrm{x}$-axis represents the different thresholds. The results of Cox's proportional hazards models are presented for (A) open days [farm and voluntary waiting period (VWP) were the covariates in the model], (B) time to the first insemination (farm, VWP, and BCS at 40-60 DIM were the covariates in the model), and (C) waste days (farm and VWP were the covariates in the model); in these planes, hazard ratio $=1$ is represented by the horizontal dotted line; values of hazard ratio significantly differ $(P<$ 0.05) between CEM-positive and CEM-negative cows if the 95\% CI (blue area above and under the middle line) does not cross the dotted line. In panel D (first AI service pregnancy risk; farm and VWP were the covariates in the model) and panel E (pregnancy risk at 180 DIM; farm and VWP were the covariates in the model), differences in pregnancy risks $[\Delta$ preg risk (\%); red bars] in CEM-positive cows, as compared with CEM-negative cows (represented by the black horizontal line at $\mathrm{Y}=0$ ), are shown (logistic regression models). 

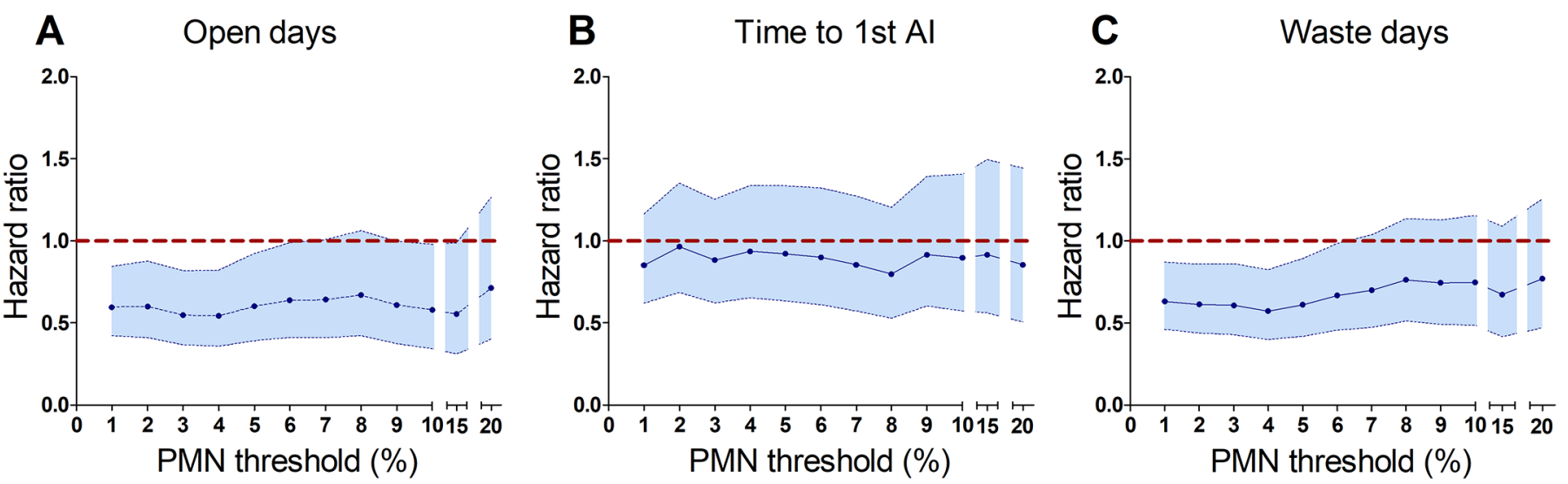

D 1st Al pregnancy risk

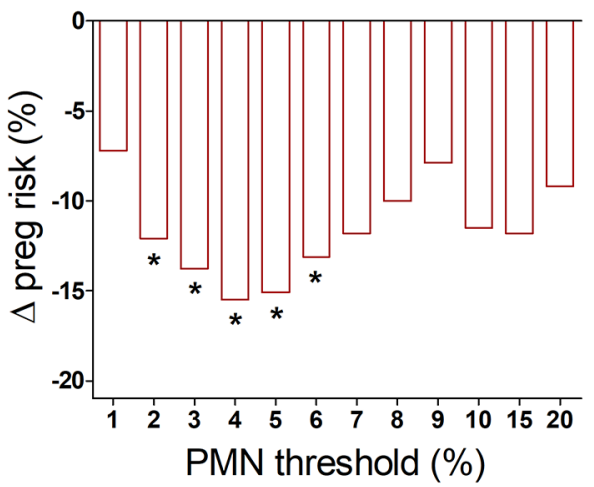

E Pregnancy risk at 180 DIM

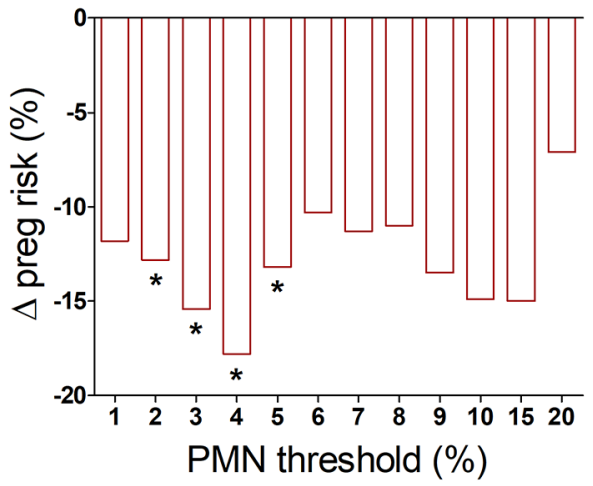

Figure 9. Reproductive performance analyses of multiparous dairy cows defined as cytological endometritis (CEM) positive versus negative by different \%PMN thresholds at 60-70 DIM. Multiparous cows were dichotomized at several \%PMN thresholds based on evaluation of endometrial cytobrush samples at 60-70 DIM, and accordingly, reproductive performance parameters were calculated and compared between CEM-positive ( $\geq$ the \%PMN threshold) versus CEM-negative cows ( $<$ the $\%$ PMN threshold). In this figure, data are presented only for the multiparous cows included in the study $(\mathrm{n}=296)$, and in all panels the $\mathrm{x}$-axis represents the different thresholds. The results of Cox's proportional hazards models are presented for (A) open days [farm and voluntary waiting period (VWP) were the covariates in the model], (B) time to the first insemination (farm, VWP, and BCS at 40-60 DIM were the covariates in the model), and (C) waste days (farm and VWP were the covariates in the model); in these planes, hazard ratio $=1$ is represented by the horizontal dotted line; values of hazard ratio significantly differ $(P<$ 0.05) between CEM-positive and CEM-negative cows if the 95\% CI (blue area above and under the middle line) does not cross the dotted line. In panel D (first AI service pregnancy risk; farm and VWP were the covariates in the model) and panel E (pregnancy risk at 180 DIM; farm and VWP were the covariates in the model) differences in pregnancy risks [ $\Delta$ preg risk (\%); red bars] in CEM-positive cows, as compared with CEM-negative cows (represented by the black horizontal line at $\mathrm{Y}=0$ ), are shown (logistic regression models). In panels $\mathrm{D}$ and $\mathrm{E}$, significant differences between CEM-positive and CEM-negative cows are marked with an asterisk $\left({ }^{*} P<0.05\right)$.

However, based on our results, the CEM diagnosis in multiparous cows was not beneficial at E35.

\section{DISCUSSION}

In the current study, we examined and compared several analytic approaches for CEM diagnosis criteria in primiparous and multiparous cows separately. Our findings support that primiparous and multiparous cows should be diagnosed for CEM by different \%PMN thresholds and sampling times in lactation. Our new approach included analyses of endometrial cytology results in 2 time points (30-40 DIM; 60-70 DIM), and their association with several reproductive performance parameters, separately for primiparous and multiparous cows. This analytic approach was performed in parallel to the traditional ROC analyses; however, our new approach identified \% PMN thresholds that showed larger differences in reproductive performance parameters between cows defined as CEM negative versus CEM positive (i.e., more parameters significantly differed, and the magnitude of differences were higher). Accordingly, our study indicates that optimal cytologic diagnosis of CEM should be performed in primiparous cows at 30-40 DIM, using a threshold of $\geq 7 \% \mathrm{PMN}$, whereas in multiparous cows, it should be at $60-70$ DIM, using 
a threshold of $\geq 4 \%$ PMN. Such a diagnostic approach provides a comprehensive view of the reproductive prognosis of CEM-positive cows, which is valuable information for management and therapeutic decisions made by farmers, veterinarians, and researchers.

Peripartum diseases are common in dairy herds, as a sequela of the calving event (Sheldon and Dobson, 2004), affected by risk factors such as metabolic status, environment, and management, which may influence the function of the immune system at the transition period and after calving (Dubuc et al., 2010b; LeBlanc, 2020). These include metritis, RFM, ketosis, low BCS, and endometritis, which are associated with negative effects on reproductive performance. Prolonged interval from calving to pregnancy has been reported to be associated with metritis (Barański et al., 2012; Giuliodori et al., 2013; Machado et al., 2020), RFM (Martin et al., 1986), ketosis (Rutherford et al., 2016), and low BCS at 40-60 DIM (van Straten et al., 2009). Ketosis, RFM, and low BCS were also associated with a prolonged interval from calving to first insemination (Martin et al., 1986; van Straten et al., 2009; Rutherford et al., 2016); and ketosis was reported to be associated with lower first AI conception rate as well (Rutherford et al., 2016). Therefore, our analytic approach of reproductive performance in CEM-positive versus -negative cows included these peripartum diseases. In accordance with previous studies on CEM in dairy cows (Kaufmann et al., 2009; Dubuc et al., 2010a; Galvão et al., 2010a), our study indicated that the increased percentage of PMN in endometrial cytology smear is associated with reduced reproductive performance in dairy cows; this association was affected by parity. Supporting evidence was found by Cheong et al. (2011) who detected negative effect of subclinical endometritis diagnosed at 40-60 DIM on reproductive performance only in multiparous but not in primiparous cows.

Kasimanickam et al. (2004) were the first to establish \%PMN thresholds for CEM based on endometrial cytobrush cytology. They performed ROC curve analyses for PMN percentage against median "days open" and reported that $\geq 18 \% \mathrm{PMN}$, and $\geq 10 \% \mathrm{PMN}$, were the thresholds they used to define CEM at 20-33 DIM and 34-47 DIM, respectively. Similarly, Madoz et al. (2013) and Galvão et al. (2009) also established \%PMN threshold based on ROC analyses; the first study indicated thresholds of $\geq 8 \%$ PMN for $21-33$ DIM, $\geq 6 \%$ PMN for 34-47 DIM, and $\geq 4 \%$ PMN for $48-62$ DIM; and the second study thresholds of $\geq 8.5 \%, \geq 6.5 \%$, and $\geq 4.0 \%$ PMN at 21,35 , and 49 DIM, respectively. In the current study, ROC curve analysis thresholds were lower than these previous studies, $3.3 \%$ at $30-40$ DIM and $1 \%$ at $60-70$ DIM, based on a dichotomous outcome of nonpregnancy by 180 DIM. Different studies used different cows and herds, with different locations, management, and many other influencing factors, which are expected to affect the results. Furthermore, the previous studies mentioned above used a different time range to dichotomous their cows, from 100-150 DIM based on median open days (Kasimanickam et al., 2004; Madoz et al., 2013), or based on the middle of the observation period (Galvão et al., 2010b). Therefore, comparing the thresholds revealed among these studies without standardization to a reference outcome is challenging. The calculated sensitivity in those studies was low, but specificity was higher, in agreement with the current study and other studies (Barlund et al., 2008; Dubuc et al., 2010a; Bogado Pascottini et al., 2017). In most previous studies that utilized ROC analysis, the threshold was selected automatically based on the best combined sensitivity and specificity. However, it is important to note that one could use a different approach, such as selecting a threshold based on high specificity or high sensitivity, depending on the goals of diagnosing cows with CEM. Furthermore, measuring sensitivity and specificity can be done only by using dichotomous reproductive performance parameters, and there is a lack of a good gold standard for CEM diagnosis. Therefore, diagnostic approach for CEM is expected to have low sensitivity since conception failures have further various independent reasons, such as metritis and other periparturient diseases (Sheldon and Dobson, 2004), ketosis (Rutherford et al., 2016), BCS (van Straten et al., 2009), and management (McDougall et al., 2014), resulting in a relatively high rate of false-negative results. In the current study, the thresholds revealed from the highest summation of sensitivity and specificity using a ROC curve analysis had low sensitivity and specificity values and relatively smaller differences in reproductive performance between CEMpositive and CEM-negative cows, as compared with the differences indicated by the thresholds revealed from our new approach. Moreover, the thresholds revealed according to the ROC analyses varied, and they were based on small differences of practically few PMN cells in the cytological smear between primiparous and multiparous cows at the 2 time points. For example, the threshold revealed for diagnosing CEM for all the cows at $60-70$ DIM was $0.3 \%$ (resulted from the count of 300 cells), meaning a single PMN cell on the cytological smear that easily can be missed even by an experienced observer. On the other hand, round off the result to an integer number (i.e., 1\%) will be more practical, especially when counting less than 300 cells; however, in this scenario, it will triple the result revealed from the ROC analysis. The area under the ROC curve is a single scalar value that measures the overall performance of a binary classifier (Hanley and McNeil, 1982); 
it can range from 0.5 to 1 , where lower values represent more random classifiers and higher values represent more precise classifiers. In our study, the areas under the curves were much closer to 0.5 than to 1 , similar to that reported in previous studies (Pascottini et al., 2016; Lee et al., 2018; McDougall et al., 2020), and which question the suitability of this analytic approach to evaluate CEM thresholds. Overall, these led us to search for a broader analytic alternative to establish \%PMN thresholds. Accordingly, our new approach included analyses of endometrial cytology results in 2 time points (30-40 DIM; 60-70 DIM) and their association with several reproductive performance parameters for primiparous and multiparous cows separately.

Barlund et al. (2008) and Dubuc et al. (2010a) combined a few reproductive performance analyses while establishing \% PMN thresholds in their studies, including validation in the Cox proportional hazard model of time to pregnancy; the \% PMN thresholds used in their studies were 8\% PMN at 28-41 DIM (Barlund et al., 2008), and 6\% PMN and $4 \%$ PMN at 32-38DIM and 53-59DIM (Dubuc et al., 2010a), respectively. In the current study, our new approach was to search for thresholds that yielded the greatest and most remarkable absolute differences that are statistically significant between CEM-positive versus -negative cows in as many of the reproductive performance parameters. This approach indicated a $\% \mathrm{PMN}$ threshold of $\geq 4 \%$ at 30-40 DIM and 60-70 DIM for all the cows together; however, when threshold analyses were performed separately for primiparous and for multiparous cows, it was found to be $7 \%$ at 30-40 DIM in primiparous cows, and $4 \%$ at $60-70$ DIM in multiparous cows. The latter thresholds for CEM diagnosis, separately for primiparous and multiparous cows, were much more strongly associated with inferior reproductive performance in cows defined as CEM positive versus negative, as than the $4 \%$ threshold for all cows regardless of parity. These findings support our hypothesis regarding possible different CEM diagnostic criteria, which was postulated based on previous studies indicating overall differences in uterine involution (Bastidas et al., 1984; Melendez et al., 2004; Zhang et al., 2010), ovarian function (LópezHelguera et al., 2016; Morales Piñeyrúa et al., 2018), peripartum metabolic status (Morales Piñeyrúa et al., 2018), and reproductive performance (Gröhn and Rajala-Schultz, 2000) between primiparous and multiparous cows. This was further supported by the fact that parity came out as a significant factor in our initial statistical analysis model, as detailed above.

It has been reported that the percentage of PMN in the uterus of dairy cows decreases as uterine involution progresses (Prunner et al., 2014; Tanai et al., 2020). Furthermore, measuring the rate of physical uterine in- volution by transrectal palpation and ultrasonography has demonstrated that involution is completed earlier in primiparous than in multiparous cows (Hajurka et al., 2005; Baez et al., 2016; Sharma et al., 2018). Similarly, primiparous women have a faster uterine involution than multiparous women, and it has been suggested that clinical subinvolution among multiparous patients may not indicate underlying complications of the puerperium (Wachsberg et al., 1994; Negishi et al., 1999; Olayemi et al., 2002). Therefore, it is reasonable to assume that in our study, multiparous cows could have been in a relatively earlier stage of uterine involution at 30-40 DIM and that the PMN percentage at that stage does not necessarily represent a disease status in those cows. Indeed, at that stage, there were more multiparous cows with high percentages of PMN than primiparous cows. Furthermore, reproductive performance parameters of multiparous cows defined as CEM positive did not differ from CEM-negative multiparous cows at any of the thresholds used at 30-40 DIM (as illustrated in Figure 8). In contrast, primiparous cows are expected to be in a relatively more advanced uterine involution stage at 30-40 DIM. Therefore, the assessment of \% PMN in their endometrial cytology appears to be a reliable method, at that stage, to define CEM. Overall, our findings support the hypothesis that the assessment of CEM by endometrial cytology, as a predictor of reproductive performance, optimally should be made within a physiologic window of uterine involution, and not necessarily in a fixed postpartum timing to all cows together.

As demonstrated in this study, our approach of evaluating endometrial cytology, using different time points in lactation, and different \%PMN thresholds, for CEM diagnosis in primiparous and multiparous cows was more strongly associated with the cows' reproductive performance compared with pulling primiparous and multiparous cows together. Additional studies are warranted to investigate differences in uterine involution between primiparous and multiparous cows, including histologic, transcriptomic, and proteomic information, in normal and disease conditions. In the dairy industry, there is a debate as to whether all cows should be examined for CEM by cytobrush in view of cost-benefit considerations. From a practical point of view, our approach can be relevant for all cows, but also for cows at risk or for cases of low reproductive performance at the herd level that require investigation. Therefore, future studies of therapeutic approaches for CEM should consider using our criteria, as well as the analytic approach of evaluating several reproductive performance parameters, and separately for primiparous and multiparous cows. Still, one may argue that performing multiple comparisons may slightly increase the chance for type I 
error; therefore, using this approach, a hypothesis may be accepted only if several outcome measures show the same direction; as many significant outcome measures are found, the strength in the hypothesis increases (such as in our results). Our study suggests that using our diagnosis criteria, the endometrial status at $60-70$ DIM might be more critical for multiparous since this can be at the end of the VWP and since it reflects lower reproductive performance. Future studies should consider whether specifically multiparous cows can optimally be diagnosed for CEM earlier than 60 DIM (e.g., 50 DIM), which potentially can add some time for treatment and recovery before the end of the VWP.

In summary, in the current study, we examined and compared thresholds resulting from several analytic approaches. Overall, our study indicated that optimally, primiparous and multiparous cows should be diagnosed for CEM by different \%PMN thresholds and sampling timings. By evaluating the association of such diagnosis with multiple reproductive performance parameters, our study indicated that optimal cytologic diagnosis of CEM should be performed in primiparous cows at 30-40 DIM, using a threshold of $\geq 7 \%$ PMN, whereas in multiparous cows it should be at 60-70 DIM, using a threshold of $\geq 4 \% \mathrm{PMN}$. The suggested approach provides a comprehensive view of the reproductive prognosis of CEM-positive cows, which is valuable information for veterinarians, farmers, and researchers. Proper diagnosis criteria for cytological endometritis may have substantial effects on cow prognosis and management, as well as on the assessment of results obtained from relevant research studies and the potential benefit for the developing therapies and prevention tools to reduce the negative effects of CEM on reproductive performance and animal welfare.

\section{ACKNOWLEDGMENTS}

The authors thank all farmers for allowing us to conduct the research in their farm, and Nathalie Weizmann (Koret School of Veterinary Medicine, Hebrew University of Jerusalem, Rehovot, Israel) for technical help and editing. This study was supported by The Israel Dairy Board Fund (Yehud, Israel; grant no. 705-006414) and by the Hebrew University (Jerusalem, Israel). The authors have not stated any conflicts of interest.

\section{REFERENCES}

Baez, G. M., R. V. Barletta, J. N. Guenther, J. M. Gaska, and M. C. Wiltbank. 2016. Effect of uterine size on fertility of lactating dairy cows. Theriogenology 85:1357-1366. https://doi.org/10.1016/j .theriogenology.2015.04.022.

Barański, W., M. Podhalicz-Dziegielewska, S. Zdunczyk, and T. Janowski. 2012. The diagnosis and prevalence of subclinical endo- metritis in cows evaluated by different cytologic thresholds. Theriogenology 78:1939-1947. https://doi.org/10.1016/j.theriogenology 2012.07.018.

Barlund, C. S., T. D. Carruthers, C. L. Waldner, and C. W. Palmer. 2008. A comparison of diagnostic techniques for postpartum endometritis in dairy cattle. Theriogenology 69:714-723. https://doi .org/10.1016/j.theriogenology.2007.12.005.

Bastidas, P., J. Troconiz, O. Verde, and O. Silva. 1984. Effect of restricted suckling on ovarian activity and uterine involution in Brahman cows. Theriogenology 21:525-532. https://doi.org/10 .1016/0093-691X(84)90437-0.

Ben Meir, Y. A., M. Nikbachat, S. Jacoby, Y. Portnik, H. Levit, A. K. Elazary, E. Gershon, G. Adin, M. Zinder-Cohen, A. Shabtay, M. Zachut, S. J. Mabjeesh, I. Halachmi, and J. Miron. 2019. Effect of lactation trimester and parity on eating behavior, milk production and efficiency traits of dairy cows. Animal 13:1736-1743. https:// doi.org/10.1017/S1751731118003452.

Bogado Pascottini, O., M. Hostens, P. Sys, P. Vercauteren, and G. Opsomer. 2017. Cytological endometritis at artificial insemination in dairy cows: Prevalence and effect on pregnancy outcome. J. Dairy Sci. 100:588-597. https://doi.org/10.3168/jds.2016-11529.

Cheong, S. H., D. V. Nydam, K. N. Galvao, B. M. Crosier, and R. O. Gilbert. 2011. Cow-level and herd-level risk factors for subclinical endometritis in lactating Holstein cows. J. Dairy Sci. 94:762-770. https://doi.org/10.3168/jds.2010-3439.

de Boer, M. W., S. J. LeBlanc, J. Dubuc, S. Meier, W. Heuwieser, S. Arlt, R. O. Gilbert, and S. McDougall. 2014. Invited review: Systematic review of diagnostic tests for reproductive-tract infection and inflammation in dairy cows. J. Dairy Sci. 97:3983-3999. https: //doi.org/10.3168/jds.2013-7450.

Deguillaume, L., A. Geffre, L. Desquilbet, A. Dizien, S. Thoumire, C. Vorniere, F. Constant, R. Fournier, and S. Chastant-Maillard. 2012. Effect of endocervical inflammation on days to conception in dairy cows. J. Dairy Sci. 95:1776-1783. https://doi.org/10.3168/ jds.2011-4602.

Dohoo, I., W. Martin, and H. Stryhn. 2014. Veterinary Epidemiologic Research. 2nd ed. VER Inc.

Druker, S., R. Sicsic, M. van Straten, T. Goshen, M. Kedmi, and T. Raz. 2021. Cytological endometritis diagnosis in primiparous versus multiparous dairy cows - supplementary material. https://doi .org/10.5281/zenodo.5507320.

Dubuc, J., T. F. Duffield, K. E. Leslie, J. S. Walton, and S. J. LeBlanc. 2010a. Definitions and diagnosis of postpartum endometritis in dairy cows. J. Dairy Sci. 93:5225-5233. https://doi.org/10.3168/ jds.2010-3428.

Dubuc, J., T. F. Duffield, K. E. Leslie, J. S. Walton, and S. J. LeBlanc. 2010b. Risk factors for postpartum uterine diseases in dairy cows. J. Dairy Sci. 93:5764-5771. https://doi.org/10.3168/jds.2010 -3429 .

Edmonson, A. J., I. J. Lean, L. D. Weaver, T. Farver, and G. Webster. 1989. A body condition scoring chart for Holstein dairy cows. J. Dairy Sci. 72:68-78. https://doi.org/10.3168/jds.S0022 -0302(89)79081-0.

Fodor, I., G. Gabor, Z. Lang, Z. Abonyi-Toth, and L. Ozsvari. 2019. Relationship between reproductive management practices and fertility in primiparous and multiparous dairy cows. Can. J. Vet. Res. 83:218-227.

Galvão, K. N., M. J. Flaminio, S. B. Brittin, R. Sper, M. Fraga, L. Caixeta, A. Ricci, C. L. Guard, W. R. Butler, and R. O. Gilbert. 2010a. Association between uterine disease and indicators of neutrophil and systemic energy status in lactating Holstein cows. J. Dairy Sci. 93:2926-2937. https://doi.org/10.3168/jds.2009-2551.

Galvão, K. N., M. Frajblat, S. B. Brittin, W. R. Butler, C. L. Guard, and R. O. Gilbert. 2009. Effect of prostaglandin F2alpha on subclinical endometritis and fertility in dairy cows. J. Dairy Sci. 92:4906-4913. https://doi.org/10.3168/jds.2008-1984.

Galvão, K. N., M. Frajblat, W. R. Butler, S. B. Brittin, C. L. Guard, and R. O. Gilbert. 2010b. Effect of early postpartum ovulation on fertility in dairy cows. Reprod. Domest. Anim. 45:e207-e211.

Gärtner, T., E. Gernand, J. Gottschalk, and K. Donat. 2019. Relationships between body condition, body condition loss, and se- 
rum metabolites during the transition period in primiparous and multiparous cows. J. Dairy Sci. 102:9187-9199. https://doi.org/10 .3168/jds.2018-15762.

Gilbert, R. O., S. T. Shin, C. L. Guard, H. N. Erb, and M. Frajblat. 2005. Prevalence of endometritis and its effects on reproductive performance of dairy cows. Theriogenology 64:1879-1888. https:// doi.org/10.1016/j.theriogenology.2005.04.022.

Giuliodori, M. J., R. P. Magnasco, D. Becu-Villalobos, I. M. LacauMengido, C. A. Risco, and R. L. de la Sota. 2013. Metritis in dairy cows: risk factors and reproductive performance. J. Dairy Sci. 96:3621-3631. https://doi.org/10.3168/jds.2012-5922.

Goshen, T., and N. Y. Shpigel. 2006. Evaluation of intrauterine antibiotic treatment of clinical metritis and retained fetal membranes in dairy cows. Theriogenology 66:2210-2218. https://doi.org/10 .1016/j.theriogenology.2006.07.017.

Gröhn, Y. T., and P. J. Rajala-Schultz. 2000. Epidemiology of reproductive performance in dairy cows. Anim. Reprod. Sci. 60-61:605614. https://doi.org/10.1016/S0378-4320(00)00085-3.

Hajurka, J., V. Macak, and V. Hura. 2005. Influence of health status of reproductive organs on uterine involution in dairy cows. Bull. Vet. Inst. Pulawy 49:53-58.

Hanley, J. A., and B. J. McNeil. 1982. The meaning and use of the area under a receiver operating characteristic (ROC) curve. Radiology 143:29-36. https://doi.org/10.1148/radiology.143.1.7063747.

Kasimanickam, R., T. F. Duffield, R. A. Foster, C. J. Gartley, K. E. Leslie, J. S. Walton, and W. H. Johnson. 2004. Endometrial cytology and ultrasonography for the detection of subclinical endometritis in postpartum dairy cows. Theriogenology 62:9-23. https:// doi.org/10.1016/j.theriogenology.2003.03.001.

Kasimanickam, R., T. F. Duffield, R. A. Foster, C. J. Gartley, K. E. Leslie, J. S. Walton, and W. H. Johnson. 2005. A comparison of the cytobrush and uterine lavage techniques to evaluate endometrial cytology in clinically normal postpartum dairy cows. Can. Vet. J. 46:255-259.

Kaufmann, T. B., M. Drillich, B. A. Tenhagen, D. Forderung, and W. Heuwieser. 2009. Prevalence of bovine subclinical endometritis $4 \mathrm{~h}$ after insemination and its effects on first service conception rate. Theriogenology 71:385-391. https://doi.org/10.1016/j .theriogenology.2008.08.005.

Kaufmann, T. B., M. Drillich, B. A. Tenhagen, and W. Heuwieser. 2010. Correlations between periparturient serum concentrations of non-esterified fatty acids, beta-hydroxybutyric acid, bilirubin, and urea and the occurrence of clinical and subclinical postpartum bovine endometritis. BMC Vet. Res. 6:47. https://doi.org/10.1186/ 1746-6148-6-47.

LeBlanc, S. J. 2008. Postpartum uterine disease and dairy herd reproductive performance: a review. Vet. J. 176:102-114. https://doi .org/10.1016/j.tvjl.2007.12.019.

LeBlanc, S. J. 2010. Assessing the association of the level of milk production with reproductive performance in dairy cattle. J. Reprod. Dev. 56(Suppl.):S1-S7. https://doi.org/10.1262/jrd.1056S01.

LeBlanc, S. J. 2020. Review: Relationships between metabolism and neutrophil function in dairy cows in the peripartum period. Animal 14(Suppl. 1):s44-s54. https://doi.org/10.1017/ S1751731119003227.

LeBlanc, S. J., T. F. Duffield, K. E. Leslie, K. G. Bateman, G. P. Keefe, J. S. Walton, and W. H. Johnson. 2002. Defining and diagnosing postpartum clinical endometritis and its impact on reproductive performance in dairy cows. J. Dairy Sci. 85:2223-2236. https://doi.org/10.3168/jds.S0022-0302(02)74302-6.

Lee, S. C., J. K. Jeong, I. S. Choi, H. G. Kang, Y. H. Jung, S. B. Park, and I. H. Kim. 2018. Cytological endometritis in dairy cows: Diagnostic threshold, risk factors, and impact on reproductive performance. J. Vet. Sci. 19:301-308. https://doi.org/10.4142/jvs 2018.19.2.301.

López-Helguera, I., M. G. Colazo, I. Garcia-Ispierto, and F. LopezGatius. 2016. Factors associated with ovarian structures and intrauterine fluid in the postpartum period in dairy cows. J. Dairy Sci. 99:3925-3933. https://doi.org/10.3168/jds.2015-10615.

López-Ratón, M., M. X. Rodríguez-Álvarez, C. C. Suárez, and F. G. Sampedro. 2014. OptimalCutpoints: An R package for select- ing optimal cutpoints in diagnostic tests. J. Stat. Softw. 61:1-36. https://doi.org/10.18637/jss.v061.i08.

Machado, V. S., M. L. Celestino, E. B. Oliveira, F. S. Lima, M. A. Ballou, and K. N. Galvao. 2020. The association of cow-related factors assessed at metritis diagnosis with metritis cure risk, reproductive performance, milk yield, and culling for untreated and ceftiofurtreated dairy cows. J. Dairy Sci. 103:9261-9276. https://doi.org/ 10.3168/jds.2020-18643.

Madoz, L. V., M. J. Giuliodori, M. Jaureguiberry, J. Plontzke, M. Drillich, and R. L. de la Sota. 2013. The relationship between endometrial cytology during estrous cycle and cutoff points for the diagnosis of subclinical endometritis in grazing dairy cows. J. Dairy Sci. 96:4333-4339. https://doi.org/10.3168/jds.2012-6269.

Martin, J. M., C. J. Wilcox, J. Moya, and E. W. Klebanow. 1986. Effects of retained fetal membranes on milk yield and reproductive performance. J. Dairy Sci. 69:1166-1168. https://doi.org/10.3168/ jds.S0022-0302(86)80517-3.

McDougall, S., D. Aberdein, A. Bates, and C. R. Burke. 2020. Prevalence of endometritis diagnosed by vaginal discharge scoring or uterine cytology in dairy cows and herds. J. Dairy Sci. 103:65116521. https://doi.org/10.3168/jds.2019-18048.

McDougall, S., C. Heuer, J. Morton, and T. Brownlie. 2014. Use of herd management programmes to improve the reproductive performance of dairy cattle. Animal 8(Suppl. 1):199-210. https://doi .org/10.1017/S1751731114000457.

McDougall, S., H. Hussein, D. Aberdein, K. Buckle, J. Roche, C. Burke, M. Mitchell, and S. Meier. 2011. Relationships between cytology, bacteriology and vaginal discharge scores and reproductive performance in dairy cattle. Theriogenology 76:229-240. https:// doi.org/10.1016/j.theriogenology.2010.12.024.

Melendez, P., J. McHale, J. Bartolome, L. F. Archbald, and G. A. Donovan. 2004. Uterine involution and fertility of Holstein cows subsequent to early postpartum PGF2alpha treatment for acute puerperal metritis. J. Dairy Sci. 87:3238-3246. https://doi.org/10 .3168/jds.S0022-0302(04)73460-8.

Morales Piñeyrúa, J. T., S. R. Farina, and A. Mendoza. 2018. Effects of parity on productive, reproductive, metabolic and hormonal responses of Holstein cows. Anim. Reprod. Sci. 191:9-21. https://doi .org/10.1016/j.anireprosci.2018.01.017.

Negishi, H., T. Kishida, H. Yamada, E. Hirayama, M. Mikuni, and S. Fujimoto. 1999. Changes in uterine size after vaginal delivery and cesarean section determined by vaginal sonography in the puerperium. Arch. Gynecol. Obstet. 263:13-16. https://doi.org/10.1007/ s004040050253.

O'Sullivan, M., B. Horan, K. M. Pierce, S. McParland, K. O'Sullivan, and F. Buckley. 2019. Milk production of Holstein-Friesian cows of divergent Economic Breeding Index evaluated under seasonal pasture-based management. J. Dairy Sci. 102:2560-2577. https:// doi.org/10.3168/jds.2018-15559.

Olayemi, O., A. A. Omigbodun, M. O. Obajimi, A. A. Odukogbe, A. M. Agunloye, C. O. Aimakhu, and M. A. Okunlola. 2002. Ultrasound assessment of the effect of parity on postpartum uterine involution. J. Obstet. Gynaecol. 22:381-384. https://doi.org/10 .1080/01443610220141317.

Pascottini, O. B., P. Dini, M. Hostens, R. Ducatelle, and G. Opsomer. 2015. A novel cytologic sampling technique to diagnose subclinical endometritis and comparison of staining methods for endometrial cytology samples in dairy cows. Theriogenology 84:1438-1446. https://doi.org/10.1016/j.theriogenology.2015.07.032.

Pascottini, O. B., M. Hostens, P. Dini, M. Van Eetvelde, P. Vercauteren, and G. Opsomer. 2016. Prevalence of cytological endometritis and effect on pregnancy outcomes at the time of insemination in nulliparous dairy heifers. J. Dairy Sci. 99:9051-9056. https://doi .org/10.3168/jds.2016-11348.

Plöntzke, J., L. V. Madoz, R. L. De la Sota, M. Drillich, and W. Heuwieser. 2010. Subclinical endometritis and its impact on reproductive performance in grazing dairy cattle in Argentina. Anim. Reprod. Sci. 122:52-57. https://doi.org/10.1016/j.anireprosci.2010 .07 .006 .

Pothmann, H., J. Muller, I. Pothmann, A. Tichy, and M. Drillich. 2019. Reproducibility of endometrial cytology using cytobrush 
technique and agreement for the diagnosis of subclinical endometritis between five predefined endometrial sites. Reprod. Domest. Anim. 54:350-357. https://doi.org/10.1111/rda.13367.

Prunner, I., H. Pothmann, K. Wagener, M. Giuliodori, J. Huber, M. Ehling-Schulz, and M. Drillich. 2014. Dynamics of bacteriologic and cytologic changes in the uterus of postpartum dairy cows. Theriogenology 82:1316-1322. https://doi.org/10.1016/j theriogenology.2014.08.018.

Robin, X., N. Turck, A. Hainard, N. Tiberti, F. Lisacek, J. C. Sanchez, and M. Muller. 2011. pROC: An open-source package for R and $\mathrm{S}+$ to analyze and compare ROC curves. BMC Bioinformatics 12:77. https://doi.org/10.1186/1471-2105-12-77.

Rojas Canadas, E., M. M. Herlihy, J. Kenneally, J. Grant, F. Kearney, P. Lonergan, and S. T. Butler. 2020. Associations between postpartum phenotypes, cow factors, genetic traits, and reproductive performance in seasonal-calving, pasture-based lactating dairy cows. J. Dairy Sci. 103:1016-1030. https://doi.org/10.3168/jds 2018-16001.

Rutherford, A. J., G. Oikonomou, and R. F. Smith. 2016. The effect of subclinical ketosis on activity at estrus and reproductive performance in dairy cattle. J. Dairy Sci. 99:4808-4815. https://doi.org/ 10.3168 /jds.2015-10154.

Schratz, P. 2017. Odds ratio calculation for GAM(M)s \& GLM(M).

Sharma, A., M. Singh, A. Sharma, and P. Kumar. 2018. Effect of BCS and parity on uterine involution, ovarian rebound and various fertility parameters in postpartum dairy cows. Indian J. Anim. Sci. 88:526-529.

Sheldon, I. M., and H. Dobson. 2004. Postpartum uterine health in cattle. Anim. Reprod. Sci. 82-83:295-306. https://doi.org/10 .1016/j.anireprosci.2004.04.006.

Sheldon, I. M., G. S. Lewis, S. LeBlanc, and R. O. Gilbert. 2006. Defining postpartum uterine disease in cattle. Theriogenology 65:1516-1530. https://doi.org/10.1016/j.theriogenology.2005.08 .021 .

Sicsic, R., T. Goshen, R. Dutta, N. Kedem-Vaanunu, V. KaplanShabtai, Z. Pasternak, Y. Gottlieb, N. Y. Shpigel, and T. Raz. 2018. Microbial communities and inflammatory response in the endometrium differ between normal and metritic dairy cows at 5-10 days post-partum. Vet. Res. 49:77. https://doi.org/10.1186/ s13567-018-0570-6.

Tanai, S., N. Endo, and T. Tanaka. 2020. Quantifying the C-reactive protein concentrations of uterine lavage samples in postpartum dairy cows. Anim. Reprod. Sci. 217:106455. https://doi.org/10 $.1016 /$ j.anireprosci.2020.106455.

Tanaka, T., M. Arai, S. Ohtani, S. Uemura, T. Kuroiwa, S. Kim, and H. Kamomae. 2008. Influence of parity on follicular dynamics and resumption of ovarian cycle in postpartum dairy cows. Anim. Re- prod. Sci. 108:134-143. https://doi.org/10.1016/j.anireprosci.2007 .07.013.

Therneau, T. and P. Grambsch. 2000. Modeling Survival Data: Extending the Cox Model. Springer- Verlag.

Van Schyndel, S. J., O. Bogado Pascottini, and S. J. LeBlanc. 2018. Comparison of cow-side diagnostic techniques for subclinical endometritis in dairy cows. Theriogenology 120:117-122. https://doi .org/10.1016/j.theriogenology.2018.08.001.

van Straten, M., N. Y. Shpigel, and M. Friger. 2009. Associations among patterns in daily body weight, body condition scoring, and reproductive performance in high-producing dairy cows. J. Dairy Sci. 92:4375-4385. https://doi.org/10.3168/jds.2008-1956.

Wachsberg, R. H., A. B. Kurtz, C. D. Levine, P. Solomon, and R. J. Wapner. 1994. Real-time ultrasonographic analysis of the normal postpartum uterus: technique, variability, and measurements. J. Ultrasound Med. 13:215-221. https://doi.org/10.7863/jum.1994 .13.3.215.

Wagener, K., C. Gabler, and M. Drillich. 2017. A review of the ongoing discussion about definition, diagnosis and pathomechanism of subclinical endometritis in dairy cows. Theriogenology 94:21-30. https://doi.org/10.1016/j.theriogenology.2017.02.005.

Weigel, K. A. 2004. Improving the reproductive efficiency of dairy cattle through genetic selection. J. Dairy Sci. 87:E86-E92. https:/ /doi.org/10.3168/jds.S0022-0302(04)70064-8.

Williams, E. J., D. P. Fischer, D. U. Pfeiffer, G. C. England, D. E. Noakes, H. Dobson, and I. M. Sheldon. 2005. Clinical evaluation of postpartum vaginal mucus reflects uterine bacterial infection and the immune response in cattle. Theriogenology 63:102-117. https: //doi.org/10.1016/j.theriogenology.2004.03.017.

Yehia, S. G., E. S. Ramadan, E. A. Megahed, and N. Y. Salem. 2020. Effect of parity on metabolic and oxidative stress profiles in Holstein dairy cows. Vet. World 13:2780-2786. https://doi.org/10 .14202 /vetworld.2020.2780-2786.

Zhang, J., L. X. Deng, H. L. Zhang, G. H. Hua, L. Han, Y. Zhu, X. J. Meng, and L. G. Yang. 2010. Effects of parity on uterine involution and resumption of ovarian activities in postpartum Chinese Holstein dairy cows. J. Dairy Sci. 93:1979-1986. https://doi.org/ 10.3168/jds.2009-2626.

\section{ORCIDS}

Shaked A. Druker @ https://orcid.org/0000-0001-5519-8155

Ron Sicsic (1) https://orcid.org/0000-0002-3867-7258

Michael van Straten $\odot$ https://orcid.org/0000-0001-7449-4179

Tal Raz (ㄴ) https://orcid.org/0000-0002-8966-6110 